\title{
Using multi-scale distribution and movement effects along a montane highway to identify optimal crossing locations for a large-bodied mammal community
}

Roads are a major cause of habitat fragmentation that can negatively affect many mammal populations. Mitigation measures such as crossing structures are a proposed method to reduce the negative effects of roads on wildlife, but the best methods for determining where such structures should be implemented, and how their effects might differ between species in mammal communities is largely unknown. We investigated the effects of a major highway through south-eastern British Columbia, Canada on several mammal species to determine how the highway may act as a barrier to animal movement, and how species may differ in their crossing-area preferences. We collected track data of eight mammal species across two winters, along both the highway and pre-marked transects, and used a multi-scale modeling approach to determine the scale at which habitat characteristics best predicted preferred crossing sites for each species. We found evidence for a severe barrier effect on all investigated species. Freely-available remotely-sensed habitat landscape data were better than more costly, manually-digitized microhabitat maps in supporting models that identified preferred crossing sites; however models using both types of data were better yet. Further, in 6 of 8 cases models which incorporated multiple spatial scales were better at predicting preferred crossing sites than models utilizing any single scale. While each species differed in terms of the landscape variables associated with preferred/avoided crossing sites, we used a multi-model inference approach to identify locations along the highway where crossing structures may benefit all of the species considered. By specifically incorporating both highway and off-highway data and predictions we were able to show that landscape context plays an important role for maximizing mitigation measurement efficiency. Our results further highlight the need for mitigation measures along major highways to improve connectivity between mammal populations, and illustrate how multi-scale data can be used to identify preferred crossing sites for different species within a mammal community. 
1 Authors:

2 Richard Schuster ${ }^{1,2}$, Neurobiology and Behavior Group, Department of Zoology, Karl-

$3 \quad$ Franzens-University, A-8010 Graz, Austria

4 Heinrich Römer, Neurobiology and Behavior Group, Department of Zoology, Karl-

$5 \quad$ Franzens-University, A-8010 Graz, Austria

6 Ryan R. Germain, Centre for Applied Conservation Research, Department of Forest \&

7 Conservation Sciences, 2424 Main Mall, University of British Columbia, Vancouver,

$8 \quad$ BC, V6T 1Z4, Canada

$9{ }^{1}$ Corresponding author:

10 Richard Schuster, Centre for Applied Conservation Research, Department of Forest \&

Conservation Sciences, 2424 Main Mall, University of British Columbia, Vancouver,

BC, V6T 1Z4, Canada. Phone: +1 604822 1256. Email: mail@richard-schuster.com

${ }^{2}$ Current Address: Centre for Applied Conservation Research, Department of Forest \& Conservation Sciences, 2424 Main Mall, University of British Columbia, Vancouver, BC, V6T 1Z4, Canada.Introduction

As human-induced fragmentation of wildlife habitats continues to increase, there is a growing need to both investigate the effects of such fragmentation on animal communities and to present possible solutions to help mitigate these effects (e.g. Gonzalez et al., 1998; Crooks, 2002). Roads are a major contributor to the fragmentation of wildlife habitat around the world (e.g, North America: Trombulak \& Frissell, 2000; Underhill \& Angold, 2000; Europe: Holderegger \& Di Giulio, 2010; Selva et al., 2011; Australia: Jones, 2000), and their construction and maintenance are one of the most widespread forms of human-based habitat 
modification (Bennett, 1991; Noss \& Cooperrider, 1994). Major effects of roads on wildlife can include traffic mortality, modification of animal behavior (e.g., road avoidance), and alteration of the physical and chemical environment leading to barrier effects and habitat fragmentation (reviewed in Trombulak \& Frissell, 2000; Jaeger et al., 2005). Movement barriers such as roads can affect wildlife at several different levels; in addition to lowering individual fitness through restricted access to resources and increased mortality risk (reviewed in Fahrig \& Rytwinski, 2009), roads may also reduce gene flow between fragmented habitats and contribute to the creation of smaller subpopulations which are more vulnerable to stochastic events (Boyce, 1992; Forman \& Alexander, 1998; Jaeger et al., 2005). For example, road fragmentation is implicated as a major contributor towards the extirpation of carnivorous mammals in the Rocky Mountains of western North America (Noss et al., 1996). Thus, there is a clear need for research on predicting areas of preferred animal crossing sites to both identify appropriate locations for mitigation measures and help reduce the negative effects of roads on wildlife communities.

Most studies investigating how to apply practical mitigation measures (e.g., crossing structures such as overpasses) aimed at reducing the effects of roads on animal communities focus on predicting the landscape features of animal-vehicle collision sites (e.g. Malo, Suarez, \& Diez, 2004; Seiler, 2005). Although current funding for mitigation measures is often allocated to sites along roads where collisions have previously been reported, collision sites may not necessarily represent the areas preferentially used by wildlife to cross roads (Alexander, Waters, \& Paquet, 2005). Consequently, identifying the landscape features surrounding roads which represent both preferred and avoided animal crossing sites may help inform mitigation design and optimize animal movement between sub-populations, thereby reducing the effects of habitat fragmentation (Singleton \& Lehmkuhl, 1999; Alexander, Waters, \& Paquet, 2005). 
Previous studies on the efficiency of mitigation strategies indicate that different mammal species can be highly variable in their tolerance to human structures, suggesting that the effects of barriers such as roads and the success of mitigation strategies will also likely vary by species (Beier \& Noss, 1998; Trombulak \& Frissell, 2000). Studies investigating mitigation strategies for high-traffic areas should therefore incorporate multiple focal species and predict spatial linkages across roads at the community level (Beier, Majka, \& Spencer, 2008). In particular, modeling animal movement across multiple spatial scales may aid our understanding of preferred habitat use along roads when considering multiple species of large mammals, which may each differ in terms of habitat requirements, home range sizes, and sensitivity to road disturbance. Animals may also select movement habitat at multiple scales, as shown in migratory birds, reptiles, and large mammals (e.g. Boyce et al., 2003; Beaudry, deMaynadier, \& Hunter, 2008; McClure, Rolek, \& Hill, 2012). Therefore, studies which incorporate several spatial scales into the same analytical framework, and compare results of predicted crossing sites across multiple spatial scales may prove particularly useful in planning mitigation strategies. Because micro-habitat assessments are often costly and labor-intensive (e.g. Fearer et al., 2007), direct comparisons of the validity of predictive models generated from micro-habitat data versus macro-habitat assessments from remotely sensed data may aid future research in allocating more time and funding to the most efficient methods.

Here, we characterize preferred and avoided crossing sites of eight large-bodied mammal species along a 95km length of highway through the Purcell Mountain Range of North America. We use a multi-scale approach comparing high-resolution, manually-digitized habitat metrics with remote sensing-derived metrics at three spatial scales $(200 \mathrm{~m}, 500 \mathrm{~m}$, and $1 \mathrm{~km})$ to investigate the potential drawbacks of each method in implementing mitigation measures. Our goals for this study include identifying the habitat variables ('predictors') of preferred and avoided crossing sites for each mammal species along this highway, and 
evaluating the efficiency of using macro-habitat predictors derived from freely available remote sensing data versus manually-digitized micro-habitat maps to predict such crossing sites. To address these goals we ask the following specific questions: 1) does the highway present a movement barrier to a multi-species community of mammals, 2) do species show preference in their choice of crossing sites towards predefined landscape predictors, 3) are there preferred crossing areas for species or species groups along the highway that could potentially serve as mitigation sites, 4) are preferred versus avoided crossing sites better predicted by habitat variables generated at the macro-scale, micro-scale, or a combination of both?

\section{Methods}

\section{STUDY AREA}

Our study was conducted along Southern Trans-Provincial Highway 3 (hereafter Hwy 3) between the towns of Creston and Cranbrook, in south-eastern British Columbia, Canada (Fig. 1). The study area is located in the Purcell Mountain Range, which ranges from 620m to $2,087 \mathrm{~m}$ in elevation, and is comprised of Interior Cedar Hemlock and Interior Douglas Fir Biogeoclimatic zones (Meidinger \& Pojar, 1991). We chose this study area for its ecological importance as a trans-boundary priority area (Yellowstone to Yukon Conservation Initiative, 2013) that connects small populations of carnivores such as grizzly bears (Ursus arctos horribilis) and Canada lynx (Lynx canadensis) along the Canada - USA border. Hwy 3 bisects this important corridor, possibly leading to negative effects on the connectivity of this movement corridor for mammal populations. The average annual traffic volume (AADT) for this highway section was 3050 cars/day in 2007, with a seasonal (December to March) average of 2020 vehicles/day (British Columbia Ministry of Transportation and Infrastructure 2010). 


\section{DATA COLLECTION}

We monitored species movement through the study area by recording tracks in the snow where animals attempted to cross Hwy 3, as well as along ten transects approaching the highway, set back from any highway right-of-way (distance from transects to highway ranged from 10 to $900 \mathrm{~m}$, mean $175 \mathrm{~m}$ ). We pre-defined our transects as survey lines marked with flagging tape, roughly parallel to the highway. Highway and transect tracks were recorded over two winter seasons, January to March 2007 and December 2007 to February 2008 (all observations recorded by RS).

Highway and transect track surveys were conducted using methods similar to Van Dyke, Brocke, \& Shaw (1986), and Alexander, Waters, \& Paquet (2005). Briefly, we conducted highway crossing attempt surveys along a 95km length of Hwy 3, at least 12 hours after the last snowfall. Each survey was conducted from a moving vehicle with a speed of approximately $10-15 \mathrm{~km} / \mathrm{h}$. When a track was observed, the investigator stopped the vehicle and conducted an on-foot inspection to identify the track. In total, we investigated tracks for 12 mammal species: coyote (Canis latrans), fox (Vulpes vulpes), wolf (Canis lupus), cougar (Puma concolor), bobcat (Lynx rufus), lynx, marten (Martes americana), wolverine (Gulo gulo), elk (Cervus canadensis), moose (Alces alces), white-tailed and mule deer (Odocoileus virginianus and Odocoileus hemionus, respectively). When we were uncertain of the identity of a track, we recorded track pattern measurements, took photos and later consulted field guides (Sheldon, 1997; Elbroch, 2003) for identification. Data at a total of 463 crossing sites were georeferenced with a handheld, Garmin eTrex Summit GPS receiver (WGS 1984, \pm 10 $40 \mathrm{~m}$ ). If multiple tracks were found for one species at a single crossing area, we recorded the total track count. We also recorded the success of a crossing attempt, here defined as the presence of a continuing set of tracks on the opposite side of the road. When tracks of the 
same species were found within 300 meters of a crossing site, it was not recorded as an individual crossing attempt, but rather as a possible repeat crossing of the same individual (Alexander, Waters, \& Paquet, 2005). Surveys were suspended when continuous heavy snowfall covered tracks during data collection.

Transects were established off-road in suitable areas close to the highway. Suitability was contingent upon minimal disturbance from residential areas, and no barriers to observer access (i.e., lakes, steep terrain, fences or private property). Seven transects had a linear distance of $1 \mathrm{~km}$, while one was $2 \mathrm{~km}$ (Transect 6) and one was $5.4 \mathrm{~km}$ in length (Transect 10). Only the first kilometer of transect 10 was surveyed during the second season of data collection, and this was classified as Transect 9 for ease of data handling. We recorded tracks of the same species according to the protocol of the crossing attempt surveys, and georeferenced a total of 308 individual track locations along the transects. We surveyed transects between 12 and 96 hours after snowfall, usually starting the day following a road survey, with 5 to $7 \mathrm{~km}$ of transect being surveyed per day. Due to the limited number of tracks recorded for carnivores (coyote, bobcat, cougar, wolf, fox, lynx, marten, wolverine, see Results) we grouped all the above species into one category 'carnivores', while evaluating the remaining species of 'ungulates' (moose, elk, deer) separately for landscape variable preference models and predictive mapping, and both separately/combined for estimates of permeability across the highway.

\section{ROAD BARRIER EFFECT}

We standardized the highway crossing attempt and transect survey data by the number of 12 hour periods that had elapsed since the time of the last snowfall to correct for time effects (Thompson et al., 1989). For calculation of the road barrier effect, we standardized survey data for the highway and transects by kilometers surveyed: 


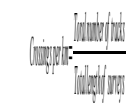

144 We then calculated the permeability of the highway by standardizing the crossings per km of

145 highway with the crossings per km of transect:

146 We also constructed track accumulation curves along the $95 \mathrm{~km}$ of highway for all four species

147 groups to identify areas of the highway with greater crossing intensity for each mammal

148 group.

149 MULTI-SCALE LANDSCAPE VARIABLES

150 To develop our micro-habitat assessments, we imported the collected GPS data into

151 ArcGIS 9.3 (ESRI, 2009). The GPS points from the highway surveys and the transect surveys

152 were set on top of a georeferenced (WGS 1984, UTM Zone 11N) orthophotograph layer from

1532004 , with a spatial resolution of 1m, provided by a Web Map Service (WMS) of GeoBC

154 (http://www.geobc.gov.bc.ca). For each GPS point, we created a circular buffer of $200 \mathrm{~m}$ to

155 represent the perceptual area of the animal directly influenced by the surrounding landscape

156 predictors (e.g. Lingle \& Wilson, 2001), which we define as 'perceptual area polygon'. For

157 each buffer area, we digitalized polygons for predefined landscape predictors and

158 georeferenced them using the orthophotograph layer and Google Earth, as the latter provided

159 more recent images of the research area. We used the following landscape predictors, adapted

160 from Dickson, Jenness, \& Beier (2005): forested (forest + woodland), shrub, herbaceous

161 (grassland + agriculture), riparian, water, non-vegetated (gravel, rock + dirt), highway

162 (+shoulder), road/path, railroad, residential, developed, disturbed and wetland (Table 1). We

163 then calculated the percentage of each buffer area overlapped by each landscape predictor.

164 Because large mammals might respond to both fine and coarse scale habitat features (e.g.

165 Mayor et al., 2007), we developed a series of variables describing macro-habitat landscape 
features at three spatial scales: $200 \mathrm{~m}, 500 \mathrm{~m}$, and $1 \mathrm{~km}$. For modeling species abundance along the highway and transects, we chose candidate predictor variables based on their ability to predict species abundance at site and landscape levels in similar studies (e.g. Malo, Suarez, \& Diez, 2004; Guisan \& Thuiller, 2005). All remotely sensed predictors (Table 1) were derived from the following sources: Terrain Resource Information Management (TRIM, Province of BC 1992) and Earth Observation for Sustainable Development Landcover (EOSD LC 2000, Wulder et al., 2008). Our dataset comprised 12 predictor variables from the perceptual area polygons and 11 from remote sensing on 3 scales $(200 \mathrm{~m}, 500 \mathrm{~m}, 1 \mathrm{~km}$; Table 1), derived at each of 463 highway locations and 308 transect locations. All remote sensing predictors were created using Geospatial Modelling Environment (Beyer, 2012) in conjunction with ArcGIS 10 (ESRI, 2010) and R v. 2.15.2 (R Development Core Team, 2012). Due to their widely varying scales, all predictors were standardized to mean $=0, \mathrm{sd}=1$ to ensure that their importance was not driven by measurement scale (White \& Burnham, 1999).

\section{LANDSCAPE VARIABLE PREFERENCE MODELS}

Since predetermining the appropriate data distribution for our count data from ecological knowledge alone was not possible, we modeled abundance incorporating both a Poisson distribution (P) and negative binomial (NB) distribution to account for potential overdispersion (e.g. Zeileis, Kleiber, \& Jackman, 2008). Because of the large proportion of zero values included in our data-set, we also applied zero-inflated models (ZIP, ZINB; Lambert, 1992), which are mixture models that combine both count data and a binomial model. To determine which of these distributions best represented our species data, we visually inspected the data and compared the log Likelihood, AIC, and number of correctly predicted zeros for each distribution model fits using intercept-only models. To test for differences among distribution functions, we used likelihood ratio tests to compare the Poisson 
and negative binomial distributions, since the Poisson distribution is a restriction of the more general negative binomial distribution (Hilbe, 2008). We tested $\mathrm{H}_{0}$ for no difference between the two and $\mathrm{H}_{1}$ that the negative binomial was a better fit to the data. We tested the same hypothesis using the zero-inflated Poisson and zero-inflated negative binomial. Next, we used a Vuong test (Vuong, 1989; Greene, 1994) to evaluate whether the zero-inflated models were a statistically better fit to the data than their base model (Hilbe, 2008). The Vuong test is generally formulated as:

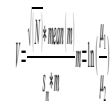

Where $\mu_{1}=$ predicted probability of $\mathrm{y}$ for the zero-inflated model, $\mu_{2}=$ predicted probability of $\mathrm{y}$ for the base model, $s_{m}=$ standard deviation of $\mathrm{m}$, and $N=$ number of observations in each model, where both must use the same observations. The test statistic V is asymptotically normal. If $\mathrm{V}>1.96$, the zero-inflated model is preferred; if $\mathrm{V}<-1.96$, the base model is preferred; and if the value of $\mathrm{V}$ is between -1.96 and 1.96 neither model is preferred (Hilbe, 2008). To perform these tests we used the function vuong in R package pscl v.1.04.4 (Zeileis, Kleiber, \& Jackman, 2008; Jackman, 2012).

We compared our measures of model selection (AIC, LogLik, predicted zeros, Vuong) for all four distributions (P, NB,ZIP, ZINB) throughout each of the model building stages of this study to avoid bias in predetermining the distribution with intercept-only models. For each of the four mammal groups (deer, elk, moose, carnivores), we compared models of predicted habitat preference using each distribution (P, NB, ZIP, ZINB) and data set (Highway, Transect) across six separate spatial approaches: i) $200 \mathrm{~m}$ scale, ii) $500 \mathrm{~m}$ scale, iii) $1 \mathrm{~km}$ scale, iv) all 3 scales combined; v) perceptual area polygons; vi) all scales and perceptual area polygons combined. For spatial approaches iv) and vi), we created an iterative model fitting procedure that starts with an intercept only base model, individually adds predictor variables, records the results of each 
213 fitted model, and retains all top-ranked models $(\triangle \mathrm{AICc} \leq 2)$ at each iteration as base models for

214 subsequent iterations as long as there is reduction in AICc ( $\mathrm{R}$ function in R-Code $\mathrm{S} 1$ ). The fitting

215 procedure constitutes an extension of a more restrictive routine that only included the top ranked

216 model for each iteration in subsequent iterations (Schuster \& Arcese, 2013). We opted for the

217 iterative approach because creating all possible models for approach iv) and vi) would have

218 resulted in $2^{\wedge} 45$ models each. For the remaining approaches, we created models for each possible

219 combination of predictors. For both ZIP and ZINB we further expanded our model lists using a)

220 intercept only models for the zero-inflation component, while using predictors in the count

221 component and b) including the same predictors for both zero-inflation and count components. In

222 post-processing we reduced the candidate set of models from each approach based on the

223 statistical significance of all predictors, using p-values as a general and liberal criterion for

224 retaining models. We selected a cutoff value of $\mathrm{p}=0.15$ as it serves as the default for many

225 stepwise model selection approaches (e.g. Rawlings, Pantula, \& Dickey, 1998). We chose this

226 approach to reduce the probability of including non-informative models (i.e., those stuck at local

227 maxima for parameter estimation) in subsequent model averaging. Additionally we checked for

228 and removed models with unrealistically high (>50) parameter estimates and/or Standard Errors,

229 which would indicate lack of model fit. For model selection, we ranked all remaining candidate

230 models by AICc and averaged those with $\triangle$ AICc $\leq 2$ from the top ranked model (Burnham

\& Anderson, 2002). All analysis were conducted using R v.2.15.2 (R Development Core Team,

232 2012); package MuMIn 1.8.0 (Barton, 2012) was used for AICc calculations; package MASS v.

233 7.3-22 (Venables \& Ripley, 2002) for NB models; and packages pscl and Formula v.1.1-0 (Zeileis

$234 \&$ Croissant, 2010) for ZIP and ZINB models.

235 To determine the distribution and scale that provided the best relative fit to the data for

236 each mammal group we compared and ranked the models with the lowest AICc of each approach 
and determined the approach resulting in the overall lowest AICc value. We further contrasted these results with the initial results from the intercept only models to determine whether initial models were sufficient to identify the error distributions that were most appropriate for a given data set or whether predictor variables had to be included first.

\section{PREDICTIVE MAPS OF PREFERRED CROSSING SITES}

Using the previous model results we created predictive maps for each species/group for both the abundance of animals approaching the highway (transect models) and the abundance of animals, having reached the highway, crossing it (highway models). For each map we chose the approach with the lowest AICc values out of the 4 remote sensing-derived frameworks (200m, $500 \mathrm{~m}, 1 \mathrm{~km}, 3$ scales), as landscape level data was not available for the perceptual area polygons. For predictive polygons, we used 30x30m polygons to follow the EOSD resolution. For the highway predictions we created polygons around the highway (line feature buffered $15 \mathrm{~m}$ on each side of highway) resulting in predictions for 7374 polygons. For transect predictions we expanded the buffer around the highway to $1 \mathrm{~km}$, resulting in 213442 polygons. Next, we generated a predictor set for each polygon centroid that was identical to those used for survey points, and then estimated abundance based on our averaged models for each of the focal species groups. We combined individual mammal group abundance estimates into 10 quantiles to consolidate focal species maps into an index of site preference, multiplied those scores for each polygon and standardized them by dividing by 1000 , resulting in community site preference scores between 0 (being the lowest preference) and 10 (highest preference).

\section{Results}




\section{ROAD BARRIER EFFECT}

Highway permeability values for the majority of groups were extremely low (where a value of 1 indicates full permeability across the highway and 0 represents no permeability), indicating that Hwy 3 likely acts as a barrier to mammal movement (Table 2). The permeability values for carnivores were only one third those of ungulates (moose, elk, deer, combined) on the investigated section of Hwy 3 (Table 2), indicating that deer, elk, and moose were much less affected by the highway in terms of movement than carnivores. Track accumulation curves for all mammal groups indicate that in all four cases there were areas of the highway where the focal group rarely or almost never crosses the highway (Figure 2).

\section{LANDSCAPE VARIABLE PREFERENCE MODELS}

Based on intercept only model comparisons using likelihood ratio tests, Vuong test and AIC ranking, the best supported distributions for each mammal group were: ZINB (Deer-Hwy, Elk-Hwy, Deer-Trans), NB (Moose-Hwy, Elk-Trans, Carnivora-Trans), ZIP (CarnivoraHwy), P (Moose-Trans), indicating that ZINB and NB were the most commonly supported distributions (Table 3 ). In 6 out of 8 cases, the modeling approach which included predictors from all three scales and the digitized polygons was selected as the top model based on AICc (Table 4). In only two cases for the transect data did other approaches result in lower AICc values: Deer (1 km scale) and Moose (500m scale). In direct comparison between predictors derived from remotely sensed data and hand digitized data, the remotely sensed model framework resulted in lower AICc values in all eight cases. When comparing the remotely 
sensed data approach at the same scale as the digitized $(200 \mathrm{~m})$ data, digitized predictors resulted in lower AICc values in 7/8 cases. A comparison of the extended modeling results (Table 4) with the initial distribution tests (Table 3 ) indicates that in $4 / 8$ cases the results from the initial tests were rejected and different distributions formed the basis of models with the lowest AICc values. For Highway and Transect data from each mammal group, model coefficients describing preferred (positive values) and avoided (negative values) habitat variables from the best supported model (above) are depicted in Tables S1 and S2. Summed values of preferred and avoided landscape variables for the entire mammal community are presented in Table 5 .

\section{PREDICTIVE MAPS OF PREFERRED CROSSING SITES}

To map preferred crossing sites, we used averaged model results for each mammal group based on the framework with the lowest AICc value out of the 4 remotely sensed model sets (Cells marked with an asterisk in Table 4; maps and shapefiles in Figures S1-S4 and Data $\mathrm{S} 2$ respectively). The combined predictions of preferred (green) and avoided (red) crossing sites for all investigated species within the mammal community are illustrated in Fig. 3. Based on predictions generated from landscape variables (above), certain regions of the study area exhibited high preference scores from both approach (transect) and crossing (highway) models (e.g., Fig. 3 insert A), indicating that these locations likely represent areas of high priority when implementing mitigation measures for all species considered in our study. Conversely, certain regions of the study area exhibited high preference scores for one of the model sets (crossing vs. approach), but not the other (e.g., Fig. 2 insert B), indicating that these may represent less-ideal locations to implement mitigation measures such as crossing structures. Areas of unambiguous preference for particular crossing sites (i.e., those where crossing and approach preference scores overlap) differ for each mammal group considered in our study 
307 (Figures S1-S4), indicating that mitigation strategies aimed at mammal communities may 308 differ substantially from those aimed at a target species.

\section{Discussion}

310 We determined that Hwy 3 posed a severe movement barrier to the local mammal community.

311 Although each investigated species differed in the landscape variables associated with

312 preferred and avoided crossing sites, we used a multi-scale approach to identify locations

313 along the highway where mitigation measures may benefit all species in the large mammal

314 community. Below we address our earlier questions and discuss the implications of our finding

315 that multi-scale habitat assessments may be necessary to accurately predict the most effective

316 locations for highway crossing structures (e.g., culverts and overpasses) or other mitigation

317 measures.

318 Permeability estimates for both carnivores and the majority of ungulate species

319 considered were extremely low across the highway (Table 2), indicating that Hwy 3 likely acts

320 as barrier to animal movement. Although permeability estimates for elk were comparatively

321 high (likely due to herding behavior, whereas tracks for all other species tended to be solitary

322 or in small groups), averaged estimates for all ungulates and the entire mammal community

323 suggest that movement by large-bodied mammals is highly restricted across the highway.

324 Likewise, track accumulation curves (Figure 2) indicate that for each species group

325 considered, certain areas of the highway may rarely or never be crossed, posing large

326 limitations to population connectivity across Hwy 3. This finding is consistent with previous

327 estimates of wildlife permeability across a similar highway through the Rocky Mountain

328 Range of Alberta, Canada (Alexander, Waters, \& Paquet, 2005). Such low permeability across

329 the highway suggests a severe threat of habitat fragmentation to the mammal community,

330 which could result in decreased gene flow across the road barrier, and ultimately to lower 
population viability in the region (Mader, 1984; Epps et al., 2005). These results indicate a need to accurately identify locations for potential mitigation measures along roads such as Hwy 3 to facilitate the movement of individuals across the highway and reduce this barrier effect (Harrison \& Bruna, 1999; Haddad et al., 2003; Crooks \& Sanjayan, 2006).

By incorporating both highway and transect predictions simultaneously, we aimed to identify locations for potential mitigation measures that represent both preferred crossing sites as well as preferred approach habitat up to $1 \mathrm{~km}$ from the highway. We determined that the landscape variables associated with preferred/avoided crossing sites differed for many of the mammal groups considered (Tables S1, S2). In all cases, noise generated from vehicles travelling on the highway could contribute to road avoidance by large mammals (Forman \& Alexander, 1998; Jaeger et al., 2005; Barber, Crooks, \& Fristrup, 2010). However, numerous studies on movement across roads by large and small mammals have found no consistent response to noise levels, and suggest that habitat characteristics surrounding crossing sites play a larger role in animal movement than individual tolerance to noise levels (McGregor, Bender, \& Fahrig, 2008; Iglesias, Mata, \& Malo, 2012). For instance, carnivores tended to avoid residential areas along the highway as well as open areas with low shrub cover (Tables S1, S2), consistent with previous studies (e.g. Mech, 1995). While elk and deer did not avoid these landscape features, these two species exhibited dissimilar patterns of habitat and crossing-site preference, consistent with their different habitat requirements (Johnson et al., 2000). These differing results per group indicate that a clear set of conservation goals for each species as well as the community as a whole must be established before mitigation measures are implemented to facilitate highway crossing (e.g. Beier, Majka, \& Spencer, 2008).

We used multi-model inference and model averaging to identify locations of preferred crossing sites for all mammal species considered, which would likely serve as the most effective locations for mitigation measures aimed at increasing mammal permeability across the highway. 
Cumulative scores of preferred/avoided landscape variables along both the highway and transect data sets indicate that preferred crossing sites tended to be within close proximity of water and longer stretches of unpaved road (Table 5). Crossing-specific scores indicate a preference for longer stretches of paved roads, and approach-specific scores suggest preference for areas of high crown cover with abundant broadleaf trees, respectively. Although this approach may reduce the efficiency of predicting highway crossing sites for certain focal species, community-level approaches are increasingly advocated as a more efficient means of implementing wildlife linkages across barriers such as major roads (Beier, Majka, \& Spencer, 2008). To accomplish this goal, we applied an exhaustive model approach incorporating four separate distributions of abundance for each mammal group along Hwy 3 . In only 4 of the 8 cases considered was preselection of the y-distribution successful, indicating that an exhaustive modeling approach incorporating multiple distributions may be necessary when the goal is to identify and predict preferred crossing sites based on limited data and uncertainties regarding which abundance distributions are most applicable to free-living animal populations. By adopting the approach described here, researchers may be able to extract more information from highway crossing data than could otherwise be gained from applying predefined and potentially inaccurate abundance distributions. Further, the best-supported distribution differed for each species; while ZINB and NB were the most commonly supported distributions, NB, ZIP and P each received the best support for at least one data set (highway versus transect). These results once again highlight the need for future studies to consider the unique habitat requirements of each species within mammal communities when developing mitigation strategies, but that those strategies which provide the greatest benefit to the largest number of species should be given priority for implementation.

To establish conservation-based goals for large mammals along roads such as Hwy 3 , further consideration must be given to whether the spatial scales at which habitat characteristics 
are measured match the spatial scales at which the animals select preferred/avoided crossing sites. We determined that in $6 / 8$ cases, a combined approach to modeling preferred crossing sites (incorporating remotely sensed and hand-digitized predictors) resulted in the best supported model. Further, utilizing multi-scale remote sensing-derived predictors always resulted in better model support than utilizing only hand-digitized predictors for each species and data set considered. Thus, our results indicate that while a combined approach may represent the most informative method for predicting landscape variables of preferred mammal crossing sites, freely-available macro-habitat data such as those generated through remote sensing may be more useful than labor-intensive micro-habitat assessments when time and budgetary constraints on data collection are imposed. Previous studies investigating habitat occupancy in birds have found similar results (e.g. McClure, Rolek, \& Hill, 2012; Meiman et al., 2012), highlighting the increasing usefulness of remote sensing in evaluating localized questions in conservation and community ecology.

The goal of our study was to identify locations along Hwy 3 where mitigation measures might increase connectivity across the highway for all species in the mammal community. Although we do not currently have data on which mitigation measures may be the most effective on increasing permeability in this system, previous studies investigating the costs/benefits of different mitigation strategies at the community level (e.g. Clevenger \& Waltho, 2000, 2005) indicate that a diversity of crossing structures of different sizes may best serve large mammal communities. Because our permeability estimates were based on snow tracks and not on data for the entire year, there is the potential for our results to only be applicable for winter months. Further, because our permeability estimates are based on transects with a mean distance of $175 \mathrm{~m}$ from the highway, we likely overestimate permeability in certain cases by not considering the density of animals in areas further away from the highway. For instance, Dickson \& Beier (2002) determined that cougars typically avoid high speed roads at a distance of $500 \mathrm{~m}-1 \mathrm{~km}$ and more 
generally, mammal populations might be influenced by human infrastructure up to about $5 \mathrm{~km}$ (Benítez-López, Alkemade, \& Verweij, 2010). Although conducting further transects at a greater distance from the road may improve estimates of habitat preference for each species along Hwy 3 , we believe our methods represent a realistic investigation of the types of habitat used by animals approaching and ultimately crossing the road, which may help inform strategies for implementing crossing structures. A potential limitation to our approach of determining the most appropriate locations for multi-species crossing structures is that preferred landscape traits differed among groups, indicating that some species would benefit less from crossing sites that serve the majority (for species specific preferences see Figures S1-S4). While the specifics of which species should be given priority in such an instance will depend on the conservation goals of managers, our method presents a potentially viable way of increasing highway permeability for multiple species, and ultimately improving connectivity and population viability for mammal communities along major roadways.

Although our study was limited to one section of highway, its importance as a wildlife corridor suggests that our approach may be widely applicable to other areas where roads bisect important wildlife habitat. In situations where managers are capable of implementing mitigation measures aimed at increasing cross-road permeability for multiple mammal species, future studies should seek to evaluate the efficiency of this method over traditional single-species approaches. Specifically, to verify the effectiveness of our approach compared to a single- species mitigation strategy, managers would ideally implement our method in areas where traditional mitigation approaches have been in place for a number of years. By directly comparing permeability values before and after the implementation of a multiple-species mitigation approach, we may gain further insight into benefits of community-level conservation planning. Finally we would like to acknowledge that our modeling approach only constitutes one possible way of drawing inference about highway approach and crossing behavior of the 
investigated mammal community. Here, we provide a flexible but somewhat restrictive framework for predicting animal abundance. Though there is always uncertainty surrounding model choice when using a multi-scale approach, extra caution should be used when basing model choice on 'stepwise' procedures and using p-values to exclude certain models from a set. The use of AIC to rank models is currently widely applied in the literature and is assumed to be valid, but this approach only gives a relative measure of fit for comparing models. AIC does not provide a measure for predictive ability of a model, which should ideally be tested against additional data. Finally, alternatives to model averaging such as a reversible jump MCMC approach (Green, 1995) could be employed to compare results and further improve robustness of analysis.

\section{Conclusion}

Roads such as Hwy 3 represent severe barriers to animal movement and pose a major threat to wildlife habitat, but few studies investigate how or where to implement mitigation measures at the community level. We identified areas along the highway with habitat features of preferred crossing sites for eight species of large mammals, representing locations where mitigation measures may have positive effects for all species investigated. We determined that a combined approach incorporating both remotely sensed and hand-digitized landscape variables best predicted crossing site preference for most species, but that remote sensing data was always better than hand-digitized values when utilized separately. Our results indicate that a multi-scale approach may be necessary when identifying areas to implement mitigation strategies across roads, as differing habitat requirements for members of the mammal community may limit the usefulness of single-species, single-scale approaches. 

473

We thank D. Quinn for logistical support throughout data collection, S.M. Alexander for helpful advice on data collection and analysis, and W. Desch for initial methodological and statistical advice. F. Suppan, P. Beier, J. Jenness and K. Crooks provided feedback on GISanalyses, and A.E. Passmore helped edit a previous version of this manuscript. We thank G. Stewart, P. Beier, and two anonymous reviewers for comments and suggestions on an earlier draft of this manuscript.

\section{Literature cited}

Alexander, S., Waters, N., \& Paquet, P. 2005. Traffic volume and highway permeability for a mammalian community in the Canadian Rocky Mountains. Canadian Geographer-Geographe Canadien 49(4):321-331.

Barber, J. R., Crooks, K. R., \& Fristrup, K. M. 2010. The costs of chronic noise exposure for terrestrial organisms. Trends in Ecology \& Evolution 25(3):180-189.

Barton, K. 2012. MuMIn: Multi-model inference 1.8.0, http://cran.rproject.org/package $=$ MuMIn.

Beaudry, F., deMaynadier, P. G., \& Hunter, M. L. 2008. Identifying road mortality threat at multiple spatial scales for semi-aquatic turtles. Biological Conservation 141(10):2550-2563.

Beier, P., Majka, D. R., \& Spencer, W. D. 2008. Forks in the road: Choices in procedures for designing wildland linkages. Conservation Biology 22(4):836-851.

Beier, P., \& Noss, R. F. 1998. Do habitat corridors provide connectivity? Conservation Biology 12(6):1241-1252. 
474 Benítez-López, A., Alkemade, R., \& Verweij, P. A. 2010. The impacts of roads and other 475 infrastructure on mammal and bird populations: a meta-analysis. Biological Conservation $476 \quad 143(6): 1307-1316$.

477 Bennett, A. F. 1991. Roads, roadsides and wildlife conservation: a review. In D. A. Saunders \& 478 R. J. Hobbs (Eds.), Nature Conservation 2: the Role of Corridors. (pp. 99-118). New South 479 Wales: Surrey Beatty and Sons.

480 Beyer, H. L. 2012. Geospatial Modelling Environment (Version 0.7.2.1). (software). URL: 481 http://www.spatialecology.com/gme.

482 Boyce, M. S. 1992. Population viability analysis. Annual Review of Ecology and Systematics $483 \quad 23: 481-506$.

484 Boyce, M. S., Mao, J. S., Merrill, E. H., Fortin, D., Turner, M. G., Fryxell, J., \& Turchin, P. 2003. 485 Scale and heterogeneity in habitat selection by elk in Yellowstone National Park. Ecoscience $486 \quad 10(4): 421-431$.

487 British Columbia Ministry of Transportation and Infrastructure. 2010. Traffic Data Program. 488 Burnham, K. P., \& Anderson, D. R. 2002. Model selection and multimodel inference: a practical 489 information-theoretic approach. New York, NY: Springer Verlag.

Clevenger, A. P., \& Waltho, N. 2000. Factors Influencing the Effectiveness of Wildlife Underpasses in Banff National Park, Alberta, Canada. Conservation Biology 14(1):47-56. Clevenger, A. P., \& Waltho, N. 2005. Performance indices to identify attributes of highway crossing structures facilitating movement of large mammals. Biological Conservation 121(3):453-464.

496 Conservation Biology 16(2):488-502. 
Crooks, K. R., \& Sanjayan, M. 2006. Connectivity conservation: maintaining connections for nature. In K. R. Crooks \& M. Sanjayan (Eds.), Connectivity conservation (pp. 1-20). Cambridge: Cambridge University Press.

Dickson, B., \& Beier, P. 2002. Home-range and habitat selection by adult cougars in southern California. The Journal of wildlife management 66(4):1235-1245.

Dickson, B. G., Jenness, J. S., \& Beier, P. 2005. Influence of vegetation, topography, and roads on cougar movement in southern California. Journal of Wildlife Management 69(1):264-276.

Elbroch, M. 2003. Mammal tracks \& sign: a guide to North American species. (M. Elbroch, Ed.). Stackpole Books, Pennsylvania, USA.

Epps, C. W., Palsboll, P. J., Wehausen, J. D., Roderick, G. K., Ramey, R. R., \& McCullough, D. R. 2005. Highways block gene flow and cause a rapid decline in genetic diversity of desert bighorn sheep. Ecology Letters 8(10):1029-1038.

ESRI. 2009. ArcGIS 9.3. Economic and Social Reserach Institute Inc., Redlands, CA. http://www.esri.com/.

ESRI. 2010. ArcGIS 10. Economic and Social Reserach Institute Inc., Redlands, CA. http://www.esri.com/.

Fahrig, L., \& Rytwinski, T. 2009. Effects of roads on animal abundance: an empirical review and synthesis. Ecology and Society 14:21.

Fearer, T. M., Prisley, S. P., Stauffer, D. F., \& Keyser, P. D. 2007. A method for integrating the Breeding Bird Survey and Forest Inventory and Analysis databases to evaluate forest birdhabitat relationships at multiple spatial scales. Forest Ecology and Management 243(1):128-143. Forman, R. T. T., \& Alexander, L. E. 1998. Roads and their major ecological effects. Annual Review of Ecology and Systematics 29:207-231. 
Gonzalez, A., Lawton, J. H., Gilbert, F. S., Blackburn, T. M., \& Evans-Freke, I. 1998.

Metapopulation dynamics, abundance, and distribution in a microecosystem. Science 281(5385):2045-2047.

Green, P. J. 1995. Reversible jump Markov chain Monte Carlo computation and Bayesian model determination. Biometrika 82(4):711-732.

Greene, W. H. 1994. Accounting for excess zeros and sample selection in Poisson and negative binomial regression models (p. 34). New York University Leonard N. Stern School of Business.

Guisan, A., \& Thuiller, W. 2005. Predicting species distribution: offering more than simple habitat models. Ecology Letters 8(9):993-1009.

Haddad, N. M., Bowne, D. R., Cunningham, A., Danielson, B. J., Levey, D. J., Sargent, S., \& Spira, T. 2003. Corridor use by diverse taxa. Ecology 84(3):609-615.

Harrison, S., \& Bruna, E. 1999. Habitat fragmentation and large-scale conservation: what do we know for sure? Ecography 22(3):225-232.

Hilbe, J. 2008. Negative Binomial Regression (p. 251). Cambridge University Press New York.

Holderegger, R., \& Di Giulio, M. 2010. The genetic effects of roads: A review of empirical evidence. Basic and Applied Ecology 11(6):522-531.

Iglesias, C., Mata, C., \& Malo, J. E. 2012. The Influence of Traffic Noise on Vertebrate Road Crossing Through Underpasses. Ambio 41(2):193-201.

Jackman, S. 2012. pscl: Classes and Methods for R Developed in the Political Science Computational Laboratory, Stanford University. http://pscl.stanford.edu/. Stanford, California. Jaeger, J. A. G., Bowman, J., Brennan, J., Fahrig, L., Bert, D., Bouchard, J., Charbonneau, N., Frank, K., Gruber, B., \& von Toschanowitz, K. T. 2005. Predicting when animal populations are at risk from roads: an interactive model of road avoidance behavior. Ecological Modelling 185(2-4):329-348. 
544 Johnson, B. K., Kern, J. W., Wisdom, M. J., Findholt, S. L., \& Kie, J. G. 2000. Resource

545 selection and spatial separation of mule deer and elk during spring. Journal of Wildlife 546 Management 64(3):685-697.

547 Jones, M. E. 2000. Road upgrade, road mortality and remedial measures: impacts on a 548 population of eastern quolls and Tasmanian devils. Wildlife Research 27(3):289-296.

549 Lambert, D. 1992. Zero-Inflated Poisson Regression, with an Application to Defects in 550 Manufacturing. Technometrics 34(1):1-14.

551 Lingle, S., \& Wilson, W. F. 2001. Detection and Avoidance of Predators in White-Tailed Deer 552 (Odocoileus virginianus) and Mule Deer (O. hemionus). Ethology 107(2):125-147.

553 Mader, H. J. 1984. Animal habitat isolation by roads and agricultural fields. Biological 554 Conservation 29(1):81-96.

555 Malo, J. E., Suarez, F., \& Diez, A. 2004. Can we mitigate animal-vehicle accidents using 556 predictive models? Journal of Applied Ecology 41(4):701-710.

557 Mayor, S. J., Schaefer, J. A., Schneider, D. C., \& Mahoney, S. P. 2007. Spectrum of selection: 558 new approaches to detecting the scale-dependent response to habitat. Ecology 88(7):1634-1640.

559 McClure, C. J. W., Rolek, B. W., \& Hill, G. E. 2012. Predicting Occupancy of Wintering 560 Migratory Birds : Is Microhabitat Information Necessary? The Condor 114(3):482-490.

561 McGregor, R. L., Bender, D. J., \& Fahrig, L. 2008. Do small mammals avoid roads because of 562 the traffic? Journal of Applied Ecology 45(1):117-123.

563 Mech, L. D. 1995. The challenge and opportunity of recovering wolf populations. Conservation 564 Biology 9(2):270-278.

565 Meidinger, D., \& Pojar, J. 1991. Ecosystems of British Columbia. Victoria, BC: British Columbia 566 Ministry of Forests. 
567 Meiman, S., Civco, D., Holsinger, K., \& Elphick, C. S. 2012. Comparing Habitat Models Using 568 Ground-Based and Remote Sensing Data: Saltmarsh Sparrow Presence Versus Nesting. Wetlands $56932(4): 725-736$.

570 Noss, R. F., \& Cooperrider, A. Y. 1994. Saving nature's legacy: protecting and restoring 571 biodiversity. (R. F. Noss \& A. Y. Cooperrider, Eds.). Island Press, Washington D.C., USA.

572 Noss, R. F., Quigley, H. B., Hornocker, M. G., Merrill, T., \& Paquet, P. C. 1996. Conservation 573 biology and carnivore conservation in the Rocky Mountains. Conservation Biology 10(4):949574963.

575 576

R Development Core Team. 2012. R: A language and environment for statistical computing 2.15.2, http://www.r-project.org. Vienna, Austria: R Foundation for Statistical Computing.

Rawlings, J. O., Pantula, S. G., \& Dickey, D. A. 1998. Applied Regression Analysis: A Research Tool (p. 657). Springer Verlag.

Schuster, R., \& Arcese, P. 2013. Using bird species community occurrence to prioritize forests for old growth restoration. Ecography 36(4):499-507.

Seiler, A. 2005. Predicting locations of moose-vehicle collisions in Sweden. Journal of Applied Ecology 42(2):371-382.

Selva, N., Kreft, S., Kati, V., Schluck, M., Jonsson, B.-G., Mihok, B., Okarma, H., \& Ibisch, P. L. 2011. Roadless and Low-Traffic Areas as Conservation Targets in Europe. Environmental Management 48(5):865-877.

Sheldon, L. 1997. Animal Tracks of the Rockies. (L. Sheldon, Ed.). Lone Pine Publishing, Edmonton, Canada.

Singleton, P., \& Lehmkuhl, J. 1999. Assessing wildlfie habitat connectivity in the Interstate 90 Snoqualmie Pass Corridor, Washington. In G. L. Evink, P. Garrett, \& D. Zeigler (Eds.), 
Proceedings of the third international conference on wildlife ecology and transportation (pp. 7584). Florida Department of Transportation, Tallahassee, Florida, USA.

Thompson, I. D., Davidson, I. J., Odonnell, S., \& Brazeau, F. 1989. Use of track transects to measure the relative occurrence of some boreal mammals in uncut forest and regeneration stands. Canadian Journal of Zoology-Revue Canadienne de Zoologie 67(7):1816-1823.

Trombulak, S. C., \& Frissell, C. A. 2000. Review of ecological effects of roads on terrestrial and aquatic communities. Conservation Biology 14(1):18-30.

Underhill, J., \& Angold, P. 2000. Effects of roads on wildlife in an intensively modified landscape. Environmental Reviews 8(1):21-39.

Van Dyke, F. G., Brocke, R. H., \& Shaw, H. G. 1986. Use of road track counts as indices of mountain lion Felis Concolor presence. Journal of Wildlife Management 50(1):102-109.

Venables, W. N., \& Ripley, B. D. 2002. Modern Applied Statistics with S (Fourth.). New York: Springer.

Vuong, Q. H. 1989. Likelihood Ratio Tests for Model Selection and Non-Nested Hypotheses. Econometrica 57(2):307-333.

White, G. C., \& Burnham, K. P. 1999. Program MARK: survival estimation from populations of marked animals. Bird Study 46(1 supp 1):120-139.

Wulder, M. A., White, J. C., Cranny, M., Hall, R. J., Luther, J. E., Beaudoin, A., Goodenough, D. G., \& Dechka, J. A. 2008. Monitoring Canada's forests. Part 1: Completion of the EOSD land cover project. Canadian Journal of Remote Sensing 34(6):549-562.

Yellowstone to Yukon Conservation Initiative. 2013. Y2Y Priority Areas. http://y2y.net/ourwork/priority-areas. Accessed: 2013-March-26.

Zeileis, A., \& Croissant, Y. 2010. Extended Model Formulas in R: Multiple Parts and Multiple Responses. Journal of Statistical Software 34(1):1-13. 
614 Zeileis, A., Kleiber, C., \& Jackman, S. 2008. Regression models for count data in R. Journal of 615 Statistical Software 27(8):1-25. 


\section{Table 1 (on next page)}

Predictor variable description.

Variables used in models predicting habitat variables of preferred and avoided crossing sites at $200 \mathrm{~m}, 500 \mathrm{~m}$, and $1 \mathrm{~km}$ spatial scales. Perceptual area polygons were only recorded at the $200 \mathrm{~m}$ scale and variables were hand-digitized from 1-m pixel photos. 


\begin{tabular}{|c|c|c|}
\hline Variable name & Variable decription & Source \\
\hline Forest & forested (forest + woodland) & \multirow{12}{*}{$\begin{array}{l}\text { Perceptual area } \\
\text { polygon } \\
\text { Variable units: } \\
\% \text { of } 200 m \\
\text { radius area }\end{array}$} \\
\hline Shrub & shrub & \\
\hline Herb & herbaceous (grassland + agriculture) & \\
\hline Riparian & riparian & \\
\hline Freshwater & river + lake & \\
\hline Unvegetated & non-vegetated (gravel, rock +dirt) & \\
\hline Highway & highway (+sholder) & \\
\hline Road & $\mathrm{road} / \mathrm{path}$ & \\
\hline Railroad & railroad & \\
\hline Residential & residential + developed & \\
\hline Disturbed & disturbed habitat (e.g. excavation sites) & \\
\hline Wetland PAP & wetland & \\
\hline Water & Lakes, reservoirs, rivers, streams, or salt water. & \multirow{8}{*}{$\begin{array}{c}\text { EOSD } \\
\text { Variable units: } \\
\text { area }\left[\mathrm{m}^{2}\right] \text { in } \\
\text { spatial scale } \\
\text { buffer around } \\
\text { data point }\end{array}$} \\
\hline Exposed & $\begin{array}{l}\text { River sediments, exposed soils, pond or lake sediments, } \\
\text { reservoir margins, beaches, landings, burned areas, road } \\
\text { surfaces, mudflat sediments, cutbanks, moraines, gravel } \\
\text { pits, tailings, railway surfaces, buildings and parking, or } \\
\text { other non-vegetated surfaces. }\end{array}$ & \\
\hline Low Shrub & $\begin{array}{l}\text { At least } 20 \% \text { ground cover which is at least one-third } \\
\text { shrub; average shrub height less than } 2 \mathrm{~m} \text {. }\end{array}$ & \\
\hline Wetland & $\begin{array}{l}\text { Land with a water table near/at/above soil surface for } \\
\text { enough time to promote wetland or aquatic processes; } \\
\text { Treed + Shrub + Herb }\end{array}$ & \\
\hline Herbecous & $\begin{array}{l}\text { Vascular plant without woody stem (grasses, crops, forbs, } \\
\text { gramminoids); minimum of } 20 \% \text { ground cover or one-third } \\
\text { of total vegetation must be herb. }\end{array}$ & \\
\hline $\begin{array}{l}\text { Dense conifer } \\
\text { forest }\end{array}$ & $\begin{array}{l}\text { Greater than } 60 \% \text { crown closure; coniferous trees are } \\
75 \% \text { or more of total basal area. }\end{array}$ & \\
\hline $\begin{array}{l}\text { Open conifer } \\
\text { forest }\end{array}$ & $\begin{array}{l}26-60 \% \text { crown closure; coniferous trees are } 75 \% \text { or more } \\
\text { of total basal area. }\end{array}$ & \\
\hline $\begin{array}{l}\text { Open broadleaf } \\
\text { forest }\end{array}$ & $\begin{array}{l}26-60 \% \text { crown closure; broadleaf trees are } 75 \% \text { or more } \\
\text { of total basal area. }\end{array}$ & \\
\hline $\begin{array}{l}\text { Gravel road } \\
\text { length }\end{array}$ & Road length within buffer (gravel) [m] & \multirow{3}{*}{ TRIM } \\
\hline $\begin{array}{l}\text { Paved road } \\
\text { length }\end{array}$ & Road length within buffer (paived) [m] & \\
\hline Buildings & Number of buildings within buffer & \\
\hline
\end{tabular}




\section{Table 2 (on next page)}

Permeability values for track counts of the highway and transects along Hwy 3.

Values are given for the community, ungulate and carnivore group levels as well as individual species for all tracks and individual crossings observed. A permeability value of 1.0 indicates no difference between off-road areas and the highway in terms of animal movement. 


\begin{tabular}{|c|c|c|c|c|c|c|}
\hline & $\begin{array}{c}\text { All } \\
\text { species }\end{array}$ & $\begin{array}{c}\text { Ungulate } \\
\mathbf{s}\end{array}$ & $\begin{array}{c}\text { Carnivore } \\
\mathrm{s}\end{array}$ & Deer & Elk & Moose \\
\hline all tracks & 0.284 & 0.307 & 0.106 & 0.223 & 0.895 & 0.263 \\
\hline $\begin{array}{l}\text { successful } \\
\text { crossings }\end{array}$ & 0.265 & 0.285 & 0.104 & 0.210 & 0.827 & 0.221 \\
\hline & Bobcat & Cougar & Coyote & Fox & Wolf & \\
\hline all tracks & 0.123 & 0.019 & 0.121 & 0.286 & 0 & \\
\hline $\begin{array}{l}\text { successful } \\
\text { crossings }\end{array}$ & 0.123 & 0.019 & 0.118 & 0.286 & 0 & \\
\hline
\end{tabular}




\section{Table 3 (on next page)}

Null model comparisons

Results (likelihood ratio, AICc, and Vuong tests) for initial distribution testscomparing Poisson (Poiss), negative binomial (NB), zero-inflated Poisson (ZIP), and zero-inflated negative binomial (ZINB) distributions on highway andtransect abundance for all four mammal groups. Bold values represent the lowest AIC for each comparison. Likelihood ratio were performed between Poiss and NB (as well as there respective zero inflated equivilants). Vuong tests were performed between Poiss and ZIP as well as NB and ZINB. ( $p$-values for both likelihood ratio and Vuong tests are shown in parenthesis.) 


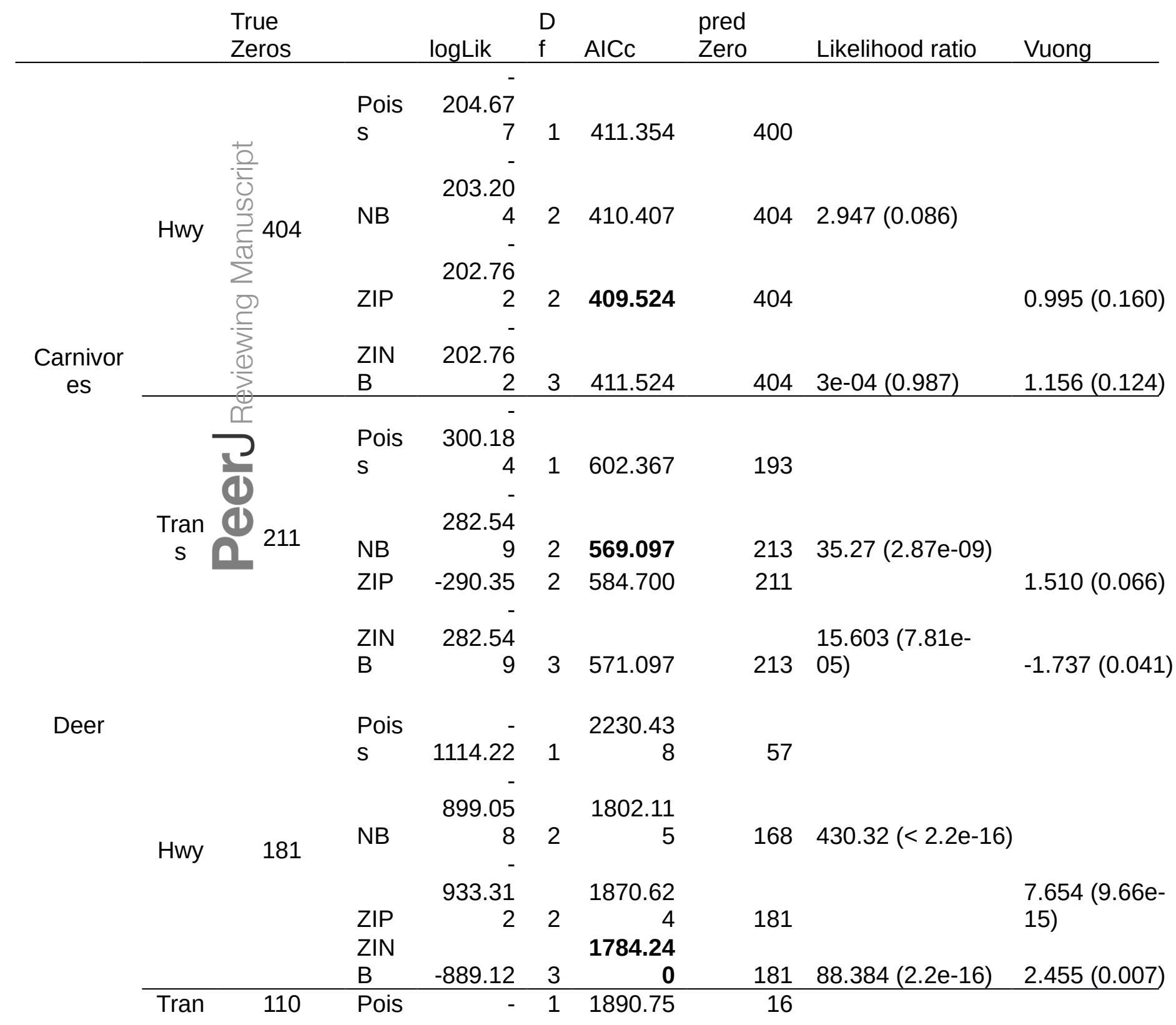




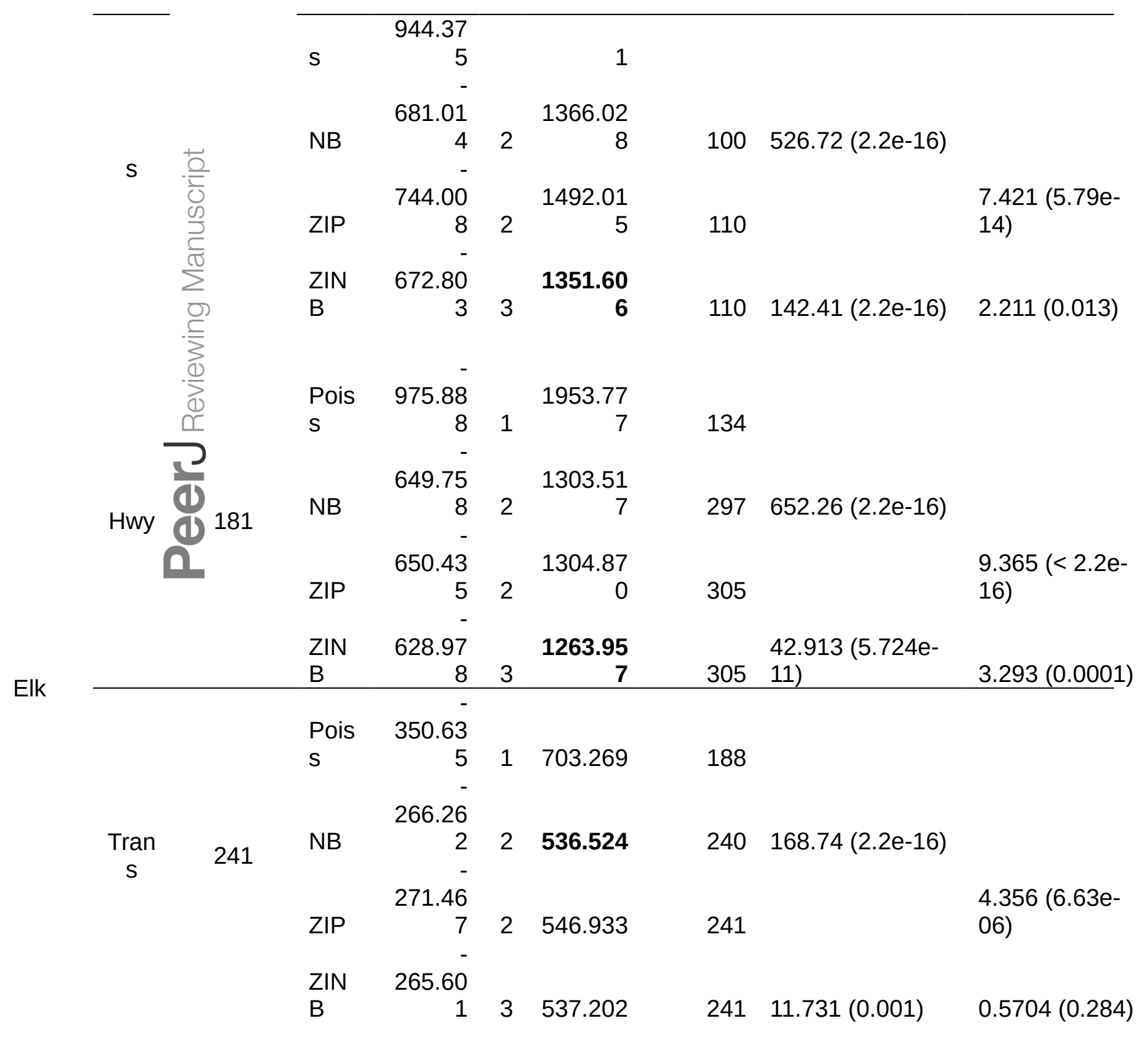




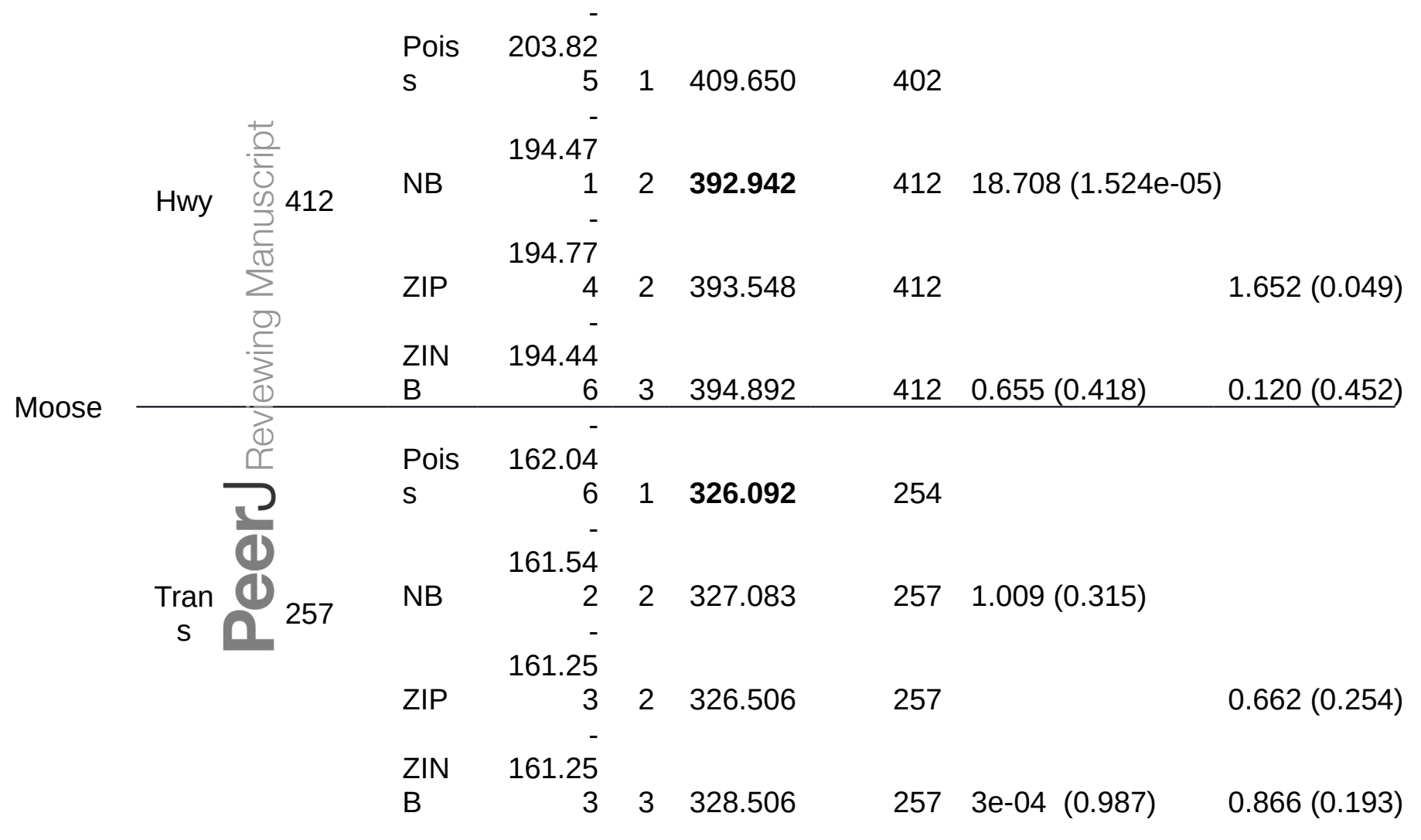




\section{Table 4 (on next page)}

Landscape variable preference model results.

Top ranked model AICc values from all model approaches used to determine landscape variable preference across six separate spatial approaches (columns) for all four mammal groups. Bold values represent the lowest AICc of the 4 distributions at one scale. Values in grey background represent the lowest AICc overall for a dataset (Hwy, Trans) and species combination. Values with an asterisk represent the approach used for creating predictive abundance maps for a dataset - species combination. 


\begin{tabular}{|c|c|c|c|c|c|c|c|c|}
\hline & & & $200 \mathrm{~m}$ & $500 \mathrm{~m}$ & $1 \mathrm{~km}$ & 3 scales & Digitized & $\begin{array}{c}\text { Combine } \\
\mathrm{d}\end{array}$ \\
\hline \multirow{8}{*}{$\begin{array}{c}\text { Carnivor } \\
\text { a }\end{array}$} & \multirow{4}{*}{ Hwy } & Poiss & 406.72 & 393.99 & 393.44 & 393.44 & 398.10 & 384.89 \\
\hline & & NB & 406.56 & 394.89 & 393.98 & 393.98 & 398.66 & 386.39 \\
\hline & & ZIP & 405.82 & 394.26 & 384.43 & $378.92^{*}$ & 398.14 & 378.96 \\
\hline & & ZINB & 407.86 & 396.29 & 386.55 & 381.03 & 400.20 & 374.81 \\
\hline & \multirow{4}{*}{ Trans } & Poiss & 581.72 & 584.91 & 584.22 & 563.26 & 570.09 & 546.26 \\
\hline & & NB & 558.44 & 559.21 & 558.78 & $547.44^{*}$ & 551.32 & 541.26 \\
\hline & & ZIP & 566.66 & 574.32 & 566.97 & 557.96 & 561.51 & 546.16 \\
\hline & & ZINB & 560.53 & 561.29 & 557.56 & 571.18 & 553.44 & 571.18 \\
\hline \multirow{8}{*}{ Deer } & \multirow{4}{*}{ Hwy } & Poiss & 2112.12 & 2113.99 & 2105.97 & 2058.87 & 2153.90 & 2046.83 \\
\hline & & NB & 1768.82 & 1770.12 & 1766.99 & 1760.42 & 1787.08 & 1760.38 \\
\hline & & ZIP & 1827.11 & 1812.58 & 1820.72 & 1807.55 & 1796.08 & 1768.06 \\
\hline & & ZINB & 1750.03 & 1739.02 & 1739.43 & 1731.62* & 1747.77 & 1707.97 \\
\hline & \multirow{4}{*}{ Trans } & Poiss & 1628.13 & 1523.81 & 1476.85 & 1417.29 & 1652.31 & 1394.78 \\
\hline & & NB & 1311.95 & 1269.85 & 1250.39 & 1237.15 & 1303.81 & 1233.78 \\
\hline & & ZIP & 1387.70 & 1321.88 & 1332.63 & 1320.64 & 1379.71 & 1309.27 \\
\hline & & ZINB & 1287.61 & 1233.46 & $1231.36^{*}$ & 1238.64 & 1269.17 & 1235.47 \\
\hline \multirow{8}{*}{ Elk } & \multirow{4}{*}{ Hwy } & Poiss & 1833.99 & 1859.39 & 1848.05 & 1754.72 & 1765.00 & 1648.51 \\
\hline & & NB & 1286.84 & 1293.10 & 1287.29 & 1279.93 & 1285.68 & 1269.56 \\
\hline & & ZIP & 1264.16 & 1273.91 & 1260.17 & 1241.21 & 1243.92 & 1213.37 \\
\hline & & ZINB & 1238.56 & 1239.10 & 1225.10 & $1225.10^{*}$ & 1235.30 & 1219.42 \\
\hline & \multirow{4}{*}{ Trans } & Poiss & 627.19 & 575.37 & 569.61 & 543.48 & 589.83 & 496.10 \\
\hline & & NB & 513.35 & 493.12 & 492.24 & 472.81 & 499.24 & 472.84 \\
\hline & & ZIP & 530.49 & 496.65 & 508.39 & 476.01 & 510.29 & 448.41 \\
\hline & & ZINB & 515.38 & 493.81 & 494.36 & 469.91* & 500.70 & 459.12 \\
\hline \multirow{8}{*}{ Moose } & \multirow{4}{*}{ Hwy } & Poiss & 396.80 & 373.96 & 371.63 & 353.20 & 353.53 & 318.84 \\
\hline & & NB & 385.73 & 365.88 & 363.09 & 351.03 & 349.29 & 320.59 \\
\hline & & ZIP & 373.22 & 351.55 & 342.48 & $331.93^{*}$ & 344.41 & 320.95 \\
\hline & & ZINB & 375.33 & 354.47 & 344.59 & 334.06 & 351.33 & 327.95 \\
\hline & \multirow{4}{*}{ Trans } & Poiss & 303.36 & 291.82* & 295.15 & 297.75 & 311.13 & 297.31 \\
\hline & & NB & 313.82 & 293.94 & 297.25 & 299.82 & 313.22 & 299.38 \\
\hline & & ZIP & 313.70 & 293.94 & 297.25 & 301.76 & 307.72 & 299.22 \\
\hline & & ZINB & 315.80 & 295.53 & 299.35 & 309.62 & 309.91 & 305.06 \\
\hline
\end{tabular}




\section{Table 5 (on next page)}

Summed importance scores of predictor variables.

The table shows how often a variable was included (as positive or negative predictor) in the eight remotely sensed modeling frameworks used to create predictive maps for Carnivora, Deer, Elk and Moose (marked with asterisks in Table 4). 


\begin{tabular}{ccccc} 
& \multicolumn{2}{c}{ Highway } & \multicolumn{2}{c}{ Transect } \\
& positiv & negativ & positiv & negativ \\
& $\mathrm{e}$ & $\mathrm{e}$ & $\mathrm{e}$ & $\mathrm{e}$ \\
\hline Water & 2 & 0 & 2 & 1 \\
Exposed & 0 & 2 & 1 & 2 \\
Low Shrub & 0 & 0 & 0 & 4 \\
Wetland & 0 & 0 & 1 & 3 \\
Herbecous & 1 & 1 & 3 & 4 \\
dense conifer forest & 0 & 0 & 2 & 2 \\
open conifer forest & 0 & 0 & 1 & 2 \\
open broadleaf & 0 & 2 & 4 & 1 \\
forest & 1 & 0 & 5 & 0 \\
gravel road length & 1 & 1 & 1 & 2 \\
paved road length & 3 & 3 & 1 & 1 \\
number of buildings & 0 & & &
\end{tabular}




\section{Figure 1}

Study Area (Cranbrook $49^{\circ} 30^{\prime} \mathrm{N}, 115^{\circ} 46^{\prime} \mathrm{W}$ ).

East Kooteney region, South eastern British Columbia, Canada. Also shown are the data collection points as well as the remote sensed (EOSD) class distribution that formed part of the model inputs. 


\section{Figure 2}

Cumulative track plots of successful crossing attempts by the four focal species groups.

Areas of no increase indicate locations along the highway where the focal group rarely or never cross the highway. This shows that for some of the focal groups there is substantial stretches of highway that represent crossing barriers. 

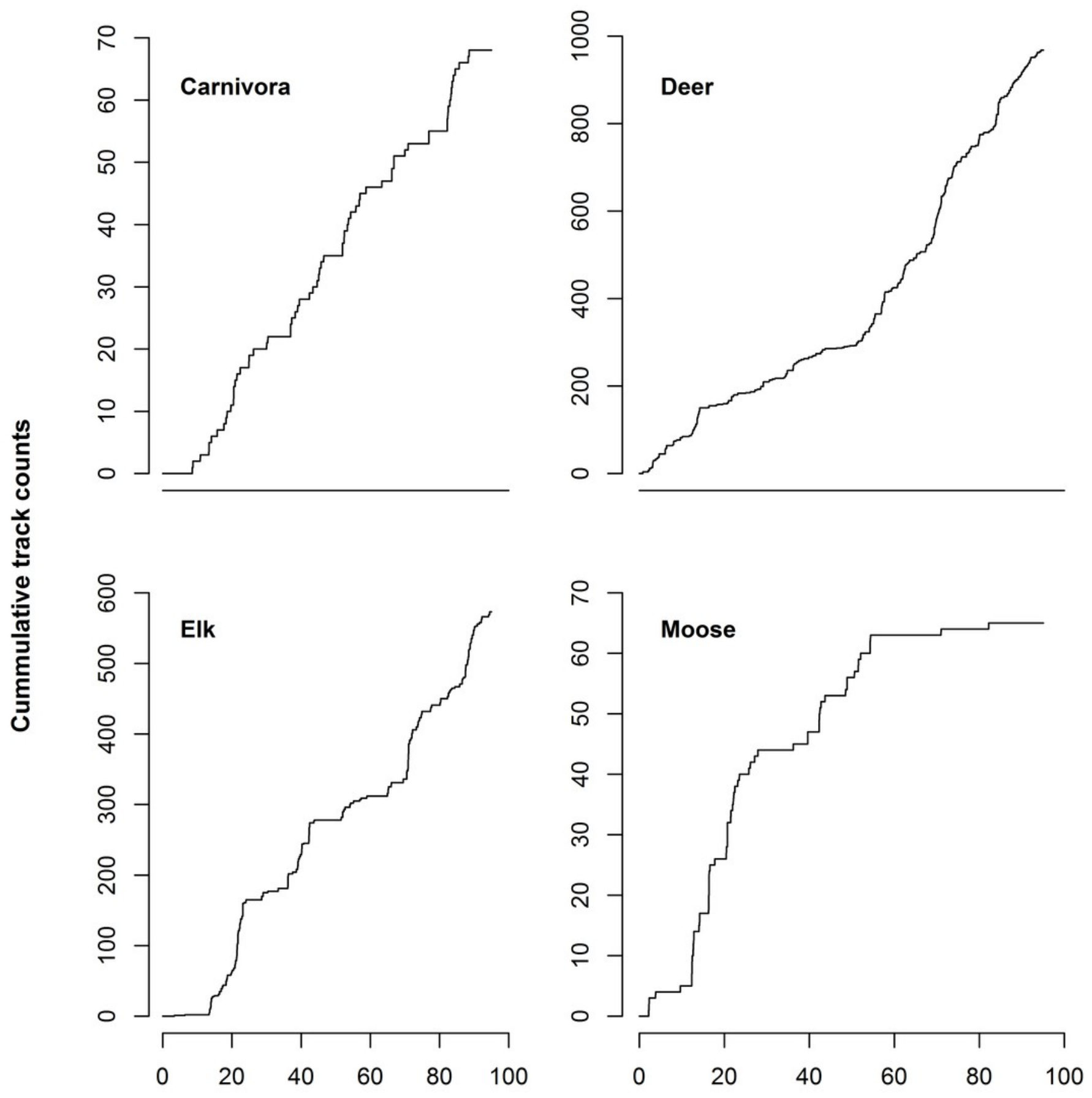

\section{Linear distance on highway [km]}




\section{Figure 3}

Community crossing site preference (green) and avoidance (red) for highway approach and actual crossing predictions

Crossing predictions are visible in inserts $A$ and $B$ as the polygons in the center within the highway outline. Results are based on averaged model results from the best remote sensed model framework for the carnivore group, deer, elk and moose. Individual model framework abundance predictions were split into 10 quantiles, multiplicatively combined and standardized by dividing by 1000 to create community scores between 0 and 10 . None of our predictions approach the maximum of 10 as no location suits all species perfectly. Insert A shows an area with high overlap between approach and crossing scores. Insert B illustrates and area of high crossing scores but low approach scores. 

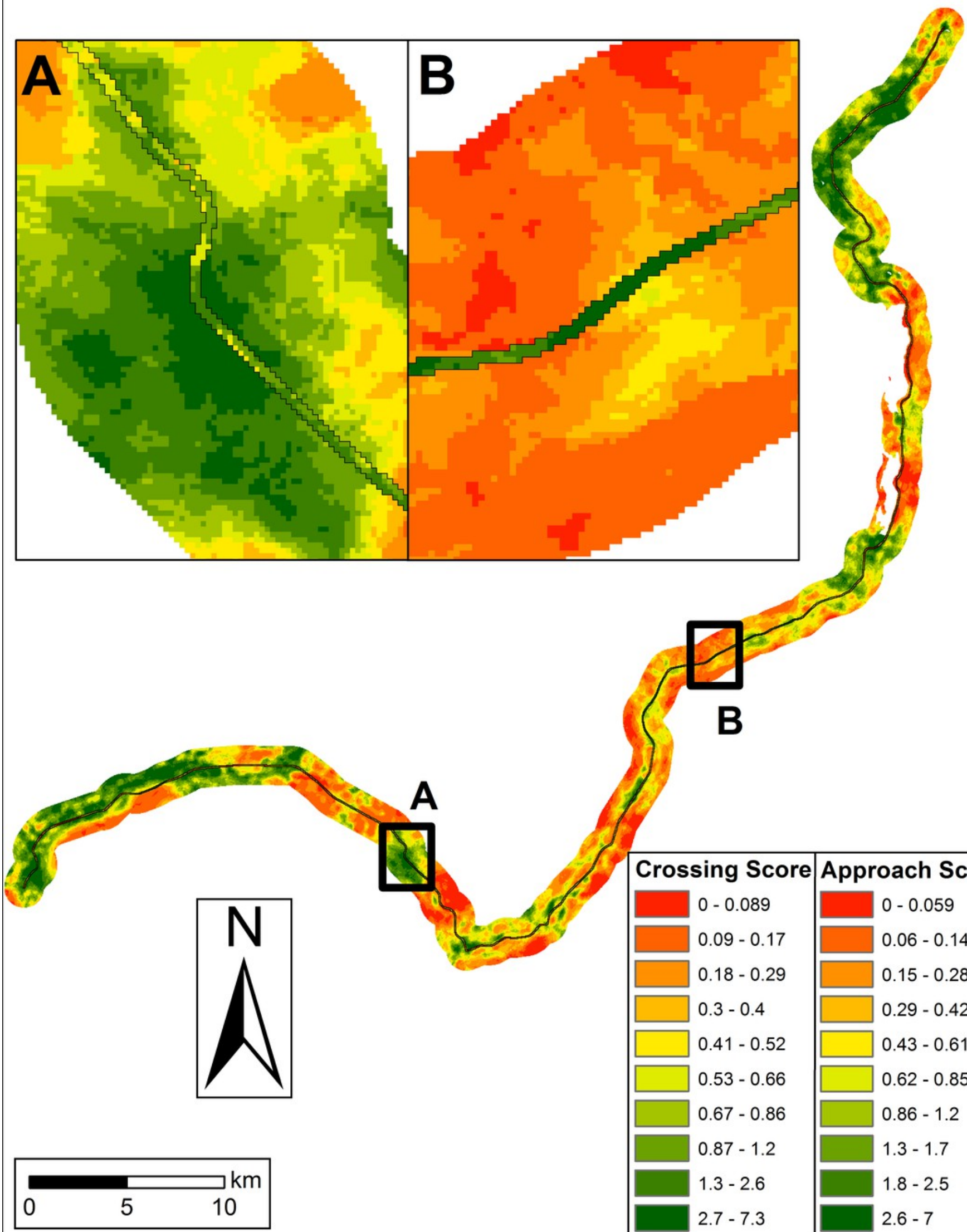

\begin{tabular}{|c|c|}
\hline Crossing Score & Approach Score \\
\hline $0-0.089$ & $0-0.059$ \\
$0.09-0.17$ & $0.06-0.14$ \\
$0.18-0.29$ & $0.15-0.28$ \\
\hline $0.3-0.4$ & $0.29-0.42$ \\
\hline$\quad 0.41-0.52$ & $\square$ \\
\hline & $0.43-0.61$ \\
\hline $0.53-0.66$ & $0.62-0.85$ \\
$0.67-0.86$ & $0.86-1.2$ \\
$0.87-1.2$ & $1.3-1.7$ \\
\hline $1.3-2.6$ & $1.8-2.5$ \\
$2.7-7.3$ & $2.6-7$ \\
\hline
\end{tabular}


1 Authors:

2 Richard Schuster ${ }^{1,2}$, Neurobiology and Behavior Group, Department of Zoology, Karl-

3 Franzens-University, A-8010 Graz, Austria

4 Heinrich Römer, Neurobiology and Behavior Group, Department of Zoology, Karl-

$5 \quad$ Franzens-University, A-8010 Graz, Austria

6 Ryan R. Germain, Centre for Applied Conservation Research, Department of Forest \& Conservation Sciences, 2424 Main Mall, University of British Columbia, Vancouver, BC, V6T 1Z4, Canada

9

10

$11{ }^{1}$ Corresponding author:

12 Richard Schuster, Centre for Applied Conservation Research, Department of Forest \& Conservation Sciences, 2424 Main Mall, University of British Columbia, Vancouver, BC, V6T 1Z4, Canada. Phone: +1 604822 1256. Email: mail@richard-schuster.com

15

$16{ }^{2}$ Current Address: Centre for Applied Conservation Research, Department of Forest \& BC, V6T 1Z4, Canada. 
Introduction

As human-induced fragmentation of wildlife habitats continues to increase, there is a growing need to both investigate the effects of such fragmentation on animal communities and to present possible solutions to help mitigate these effects (e.g. Gonzalez et al., 1998; Crooks, 2002). Roads are a major contributor to the fragmentation of wildlife habitat around the world (e.g, North America: Trombulak \& Frissell, 2000; Underhill \& Angold, 2000; Europe: Holderegger \& Di Giulio, 2010; Selva et al., 2011; Australia: Jones, 2000), and their construction and maintenance are one of the most widespread forms of human-based habitat modification (Bennett, 1991; Noss \& Cooperrider, 1994). Major effects of roads on wildlife can include traffic mortality, modification of animal behavior (e.g., road avoidance), and alteration of the physical and chemical environment leading to barrier effects and habitat fragmentation (reviewed in Trombulak \& Frissell, 2000; Jaeger et al., 2005). Movement barriers such as roads can affect wildlife at several different levels; in addition to lowering individual fitness through restricted access to resources and increased mortality risk (reviewed in Fahrig \& Rytwinski, 2009), roads may also reduce gene flow between fragmented habitats and contribute to the creation of smaller subpopulations which are more vulnerable to stochastic events (Boyce, 1992; Forman \& Alexander, 1998; Jaeger et al., 2005). For example, road fragmentation is implicated as a major contributor towards the extirpation of carnivorous mammals in the Rocky Mountains of western North America (Noss et al., 1996). Thus, there is a clear need for research on predicting areas of preferred animal crossing sites to both identify appropriate locations for mitigation measures and help reduce the negative effects of roads on wildlife communities. structures such as overpasses) aimed at reducing the effects of roads on animal communities focus on predicting the landscape features of animal-vehicle collision sites (e.g. Malo, 
Suarez, \& Diez, 2004; Seiler, 2005). Although current funding for mitigation measures is

often allocated to sites along roads where collisions have previously been reported, collision sites may not necessarily represent the areas preferentially used by wildlife to cross roads (Alexander, Waters, \& Paquet, 2005). Consequently, identifying the landscape features surrounding roads which represent both preferred and avoided animal crossing sites may help inform mitigation design and optimize animal movement between sub-populations, thereby reducing the effects of habitat fragmentation (Singleton \& Lehmkuhl, 1999; Alexander, Waters, \& Paquet, 2005).

Previous studies on the efficiency of mitigation strategies indicate that different mammal species can be highly variable in their tolerance to human structures, suggesting that the effects of barriers such as roads and the success of mitigation strategies will also likely vary by species (Beier \& Noss, 1998; Trombulak \& Frissell, 2000). Studies investigating mitigation strategies for high-traffic areas should therefore incorporate multiple focal species and predict spatial linkages across roads at the community level (Beier, Majka, \& Spencer, 2008). In particular, modeling animal movement across multiple spatial scales may aid our understanding of preferred habitat use along roads when considering multiple species of large mammals, which may each differ in terms of habitat requirements, home range sizes, and sensitivity to road disturbance. Animals may also select movement habitat at multiple scales, as shown in migratory birds, reptiles, and large mammals (e.g. Boyce et al., 2003; Beaudry, deMaynadier, \& Hunter, 2008; McClure, Rolek, \& Hill, 2012). Therefore, studies which incorporate several spatial scales into the same analytical framework, and compare results of predicted crossing sites across multiple spatial scales may prove particularly useful in planning mitigation strategies. Because micro-habitat assessments are often costly and laborintensive (e.g. Fearer et al., 2007), direct comparisons of the validity of predictive models generated from micro-habitat data versus macro-habitat assessments from remotely sensed 
data may aid future research in allocating more time and funding to the most efficient methods.

Here, we characterize preferred and avoided crossing sites of eight large-bodied mammal species along a 95km length of highway through the Purcell Mountain Range of North America. We use a multi-scale approach comparing high-resolution, manuallydigitized habitat metrics with remote sensing-derived metrics at three spatial scales $(200 \mathrm{~m}$, $500 \mathrm{~m}$, and $1 \mathrm{~km}$ ) to investigate the potential drawbacks of each method in implementing mitigation measures. Our goals for this study include identifying the habitat variables ('predictors') of preferred and avoided crossing sites for each mammal species along this highway, and evaluating the efficiency of using macro-habitat predictors derived from freely available remote sensing data versus manually-digitized micro-habitat maps to predict such crossing sites. To address these goals we ask the following specific questions: 1 ) does the highway present a movement barrier to a multi-species community of mammals, 2) do species show preference in their choice of crossing sites towards predefined landscape predictors, 3) are there preferred crossing areas for species or species groups along the highway that could potentially serve as mitigation sites, 4) are preferred versus avoided crossing sites better predicted by habitat variables generated at the macro-scale, micro-scale, or a combination of both?

\section{Methods}

\section{STUDY AREA}

Our study was conducted along Southern Trans-Provincial Highway 3 (hereafter Hwy 3) between the towns of Creston and Cranbrook, in south-eastern British Columbia, Canada

(Fig. 1). The study area is located in the Purcell Mountain Range, which ranges from 620m to 2,087m in elevation, and is comprised of Interior Cedar Hemlock and Interior Douglas Fir 
94 Biogeoclimatic zones (Meidinger \& Pojar, 1991). We chose this study area for its ecological importance as a trans-boundary priority area (Yellowstone to Yukon Conservation Initiative, 2013) that connects small populations of carnivores such as grizzly bears (Ursus arctos horribilis) and Canada lynx (Lynx canadensis) along the Canada - USA border. Hwy 3 bisects this important corridor, possibly leading to negative effects on the connectivity of this movement corridor for mammal populations. The average annual traffic volume (AADT) for this highway section was 3050 cars/day in 2007, with a seasonal (December to March) average of 2020 vehicles/day (British Columbia Ministry of Transportation and Infrastructure 2010).

\section{DATA COLLECTION}

We monitored species movement through the study area by recording tracks in the snow where animals attempted to cross Hwy 3, as well as along ten transects approaching the highway, set back from any highway right-of-way (distance from transects to highway ranged from 10 to $900 \mathrm{~m}$, mean $175 \mathrm{~m})$. We pre-defined our transects as survey lines marked with flagging tape, roughly parallel to the highway. Highway and transect tracks were recorded over two winter seasons, January to March 2007 and December 2007 to February 2008 (all observations recorded by RS).

Highway and transect track surveys were conducted using methods similar to Van Dyke, Brocke, \& Shaw (1986), and Alexander, Waters, \& Paquet (2005). Briefly, we conducted highway crossing attempt surveys along a 95km length of Hwy 3, at least 12 hours after the last snowfall. Each survey was conducted from a moving vehicle with a speed of approximately $10-15 \mathrm{~km} / \mathrm{h}$. When a track was observed, the investigator stopped the vehicle and conducted an on-foot inspection to identify the track. In total, we investigated tracks for 12 mammal species: coyote (Canis latrans), fox (Vulpes vulpes), wolf (Canis lupus), cougar 
119 (Puma concolor), bobcat (Lynx rufus), lynx, marten (Martes americana), wolverine (Gulo 120 gulo), elk (Cervus canadensis), moose (Alces alces), white-tailed and mule deer (Odocoileus

121 virginianus and Odocoileus hemionus, respectively). When we were uncertain of the identity

122 of a track, we recorded track pattern measurements, took photos and later consulted field

123 guides (Sheldon, 1997; Elbroch, 2003) for identification. Data at a total of 463 crossing sites

124 were georeferenced with a handheld, Garmin eTrex Summit GPS receiver (WGS 1984, \pm 10

$125-40 \mathrm{~m}$ ). If multiple tracks were found for one species at a single crossing area, we recorded

126 the total track count. We also recorded the success of a crossing attempt, here defined as the

127 presence of a continuing set of tracks on the opposite side of the road. When tracks of the

128 same species were found within 300 meters of a crossing site, it was not recorded as an

129 individual crossing attempt, but rather as a possible repeat crossing of the same individual

130 (Alexander, Waters, \& Paquet, 2005). Surveys were suspended when continuous heavy

131 snowfall covered tracks during data collection.

Transects were established off-road in suitable areas close to the highway. Suitability was contingent upon minimal disturbance from residential areas, and no barriers to observer access (i.e., lakes, steep terrain, fences or private property). Seven transects had a linear distance of $1 \mathrm{~km}$, while one was $2 \mathrm{~km}$ (Transect 6) and one was $5.4 \mathrm{~km}$ in length (Transect 10). Only the first kilometer of transect 10 was surveyed during the second season of data collection, and this was classified as Transect 9 for ease of data handling. We recorded tracks

138 of the same species according to the protocol of the crossing attempt surveys, and

139 georeferenced a total of 308 individual track locations along the transects. We surveyed 140 transects between 12 and 96 hours after snowfall, usually starting the day following a road 141 survey, with 5 to $7 \mathrm{~km}$ of transect being surveyed per day. Due to the limited number of 142 tracks recorded for carnivores (coyote, bobcat, cougar, wolf, fox, lynx, marten, wolverine, see

143 Results) we grouped all the above species into one category 'carnivores', while evaluating the 
144 remaining species of 'ungulates' (moose, elk, deer) separately for landscape variable

145 preference models and predictive mapping, and both separately/combined for estimates of

146 permeability across the highway.

ROAD BARRIER EFFECT

149 We standardized the highway crossing attempt and transect survey data by the

150 number of 12 hour periods that had elapsed since the time of the last snowfall to correct for

151 time effects (Thompson et al., 1989). For calculation of the road barrier effect, we

152 standardized survey data for the highway and transects by kilometers surveyed:

$$
\text { Crossings per } \mathrm{km}=\frac{\text { Toral number of tracks }}{\text { Total length of surveys }}
$$

153 We then calculated the permeability of the highway by standardizing the crossings per km of

154 highway with the crossings per km of transect:

$$
\text { Permeability }=\frac{\text { Highway crossings per } \mathrm{km}}{\text { Transect crossings per } \mathrm{km}}
$$

155 We also constructed track accumulation curves along the 95km of highway for all four

156 species groups to identify areas of the highway with greater crossing intensity for each

157 mammal group.

158

159

160

161

162

163

164

165

\section{MULTI-SCALE LANDSCAPE VARIABLES}

To develop our micro-habitat assessments, we imported the collected GPS data into ArcGIS 9.3 (ESRI, 2009). The GPS points from the highway surveys and the transect surveys were set on top of a georeferenced (WGS 1984, UTM Zone 11N) orthophotograph layer from 2004, with a spatial resolution of 1m, provided by a Web Map Service (WMS) of GeoBC (http://www.geobc.gov.bc.ca). For each GPS point, we created a circular buffer of 200m to represent the perceptual area of the animal directly influenced by the surrounding landscape predictors (e.g. Lingle \& Wilson, 2001), which we define as 'perceptual area polygon'. For 
each buffer area, we digitalized polygons for predefined landscape predictors and

167

168

169

170

georeferenced them using the orthophotograph layer and Google Earth, as the latter provided more recent images of the research area. We used the following landscape predictors, adapted from Dickson, Jenness, \& Beier (2005): forested (forest + woodland), shrub, herbaceous (grassland + agriculture), riparian, water, non-vegetated (gravel, rock +dirt), highway (+shoulder), road/path, railroad, residential, developed, disturbed and wetland (Table 1). We then calculated the percentage of each buffer area overlapped by each landscape predictor. Because large mammals might respond to both fine and coarse scale habitat features (e.g. Mayor et al., 2007), we developed a series of variables describing macro-habitat landscape features at three spatial scales: 200m, 500m, and $1 \mathrm{~km}$. For modeling species abundance along the highway and transects, we chose candidate predictor variables based on their ability to predict species abundance at site and landscape levels in similar studies (e.g. Malo, Suarez, \& Diez, 2004; Guisan \& Thuiller, 2005). All remotely sensed predictors (Table 1) were derived from the following sources: Terrain Resource Information Management (TRIM, Province of BC 1992) and Earth Observation for Sustainable Development Landcover (EOSD LC 2000, Wulder et al., 2008). Our dataset comprised 12 predictor variables from the perceptual area polygons and 11 from remote sensing on 3 scales $(200 \mathrm{~m}$, 500m, 1km; Table 1), derived at each of 463 highway locations and 308 transect locations. All remote sensing predictors were created using Geospatial Modelling Environment (Beyer, 2012) in conjunction with ArcGIS 10 (ESRI, 2010) and R v. 2.15.2 (R Development Core Team, 2012). Due to their widely varying scales, all predictors were standardized to mean=0, sd $=1$ to ensure that their importance was not driven by measurement scale (White $\&$ Burnham, 1999). 
191 Since predetermining the appropriate data distribution for our count data from ecological 192 knowledge alone was not possible, we modeled abundance incorporating both a Poisson 193 distribution (P) and negative binomial (NB) distribution to account for potential 194 overdispersion (e.g. Zeileis, Kleiber, \& Jackman, 2008). Because of the large proportion of 195 zero values included in our data-set, we also applied zero-inflated models (ZIP, ZINB;

196 Lambert, 1992), which are mixture models that combine both count data and a binomial 197 model. To determine which of these distributions best represented our species data, we 198 visually inspected the data and compared the log Likelihood, AIC, and number of correctly 199 predicted zeros for each distribution model fits using intercept-only models. To test for 200 differences among distribution functions, we used likelihood ratio tests to compare the 201 Poisson and negative binomial distributions, since the Poisson distribution is a restriction of the more general negative binomial distribution (Hilbe, 2008). We tested $\mathrm{H}_{0}$ for no difference between the two and $\mathrm{H}_{1}$ that the negative binomial was a better fit to the data. We tested the same hypothesis using the zero-inflated Poisson and zero-inflated negative binomial. Next, we used a Vuong test (Vuong, 1989; Greene, 1994) to evaluate whether the zero-inflated models were a statistically better fit to the data than their base model (Hilbe, 2008). The Vuong test is generally formulated as:

$$
\mathrm{V}=\frac{\operatorname{sqrt}(N) * \operatorname{mean}(m)}{s_{m} * m} \quad m=\ln \left(\frac{\mu_{1}}{\mu_{2}}\right)
$$

208 Where $\mu_{1}=$ predicted probability of $\mathrm{y}$ for the zero-inflated model, $\mu_{2}=$ predicted probability

209 of $\mathrm{y}$ for the base model, $s_{m}=$ standard deviation of $\mathrm{m}$, and $N=$ number of observations in

210 each model, where both must use the same observations. The test statistic V is asymptotically

211 normal. If $\mathrm{V}>1.96$, the zero-inflated model is preferred; if $\mathrm{V}<-1.96$, the base model is

212 preferred; and if the value of $\mathrm{V}$ is between -1.96 and 1.96 neither model is preferred (Hilbe,

213 2008). To perform these tests we used the function vuong in R package pscl v.1.04.4 (Zeileis,

214 Kleiber, \& Jackman, 2008; Jackman, 2012). 

for all four distributions (P, NB,ZIP, ZINB) throughout each of the model building stages of

217 this study to avoid bias in predetermining the distribution with intercept-only models. For

218 each of the four mammal groups (deer, elk, moose, carnivores), we compared models of

219 predicted habitat preference using each distribution (P, NB, ZIP, ZINB) and data set

220 (Highway, Transect) across six separate spatial approaches: i) 200m scale, ii) 500m scale, iii)

221 1km scale, iv) all 3 scales combined; v) perceptual area polygons; vi) all scales and

222 perceptual area polygons combined. For spatial approaches iv) and vi), we created an

223 iterative model fitting procedure that starts with an intercept only base model, individually

224 adds predictor variables, records the results of each fitted model, and retains all top-ranked

225 models $(\triangle \mathrm{AICc} \leq 2)$ at each iteration as base models for subsequent iterations as long as there

226 is reduction in AICc ( $\mathrm{R}$ function in R-Code S1). The fitting procedure constitutes an extension of a more restrictive routine that only included the top ranked model for each iteration in subsequent iterations (Schuster \& Arcese, 2013). We opted for the iterative approach because creating all possible models for approach iv) and vi) would have resulted in 2^45 models each. For the remaining approaches, we created models for each possible combination of predictors. For both ZIP and ZINB we further expanded our model lists using a) intercept only models for the zero-inflation component, while using predictors in the count component and b) including the same predictors for both zero-inflation and count components. In post-processing we reduced the candidate set of models from each approach based on the statistical significance of all predictors, using p-values as a general and liberal criterion for retaining models. We selected a cutoff value of $p=0.15$ as it serves as the default for many stepwise model selection approaches (e.g. Rawlings, Pantula, \& Dickey, 1998). We chose this approach to reduce the probability of including non-informative models (i.e., those stuck at local maxima for parameter estimation) in subsequent model averaging. 
240 Additionally we checked for and removed models with unrealistically high ( $>50)$ parameter

241 estimates and/or Standard Errors, which would indicate lack of model fit. For model

242 selection, we ranked all remaining candidate models by AICc and averaged those with $\triangle$ AICc

$243 \leq 2$ from the top ranked model (Burnham \& Anderson, 2002). All analysis were conducted

244 using R v.2.15.2 (R Development Core Team, 2012); package MuMIn 1.8.0 (Barton, 2012)

245 was used for AICc calculations; package MASS v. 7.3-22 (Venables \& Ripley, 2002) for NB

246 models; and packages pscl and Formula v.1.1-0 (Zeileis \& Croissant, 2010) for ZIP and

247 ZINB models.

248 To determine the distribution and scale that provided the best relative fit to the data for

249 each mammal group we compared and ranked the models with the lowest AICc of each

250 approach and determined the approach resulting in the overall lowest AICc value. We further

251 contrasted these results with the initial results from the intercept only models to determine

252 whether initial models were sufficient to identify the error distributions that were most

253 appropriate for a given data set or whether predictor variables had to be included first.

254

255

PREDICTIVE MAPS OF PREFERRED CROSSING SITES

256

Using the previous model results we created predictive maps for each species/group

257

for both the abundance of animals approaching the highway (transect models) and the

258

abundance of animals, having reached the highway, crossing it (highway models). For each

259

map we chose the approach with the lowest AICc values out of the 4 remote sensing-derived

260 frameworks (200m, 500m, 1km, 3 scales), as landscape level data was not available for the

261 perceptual area polygons. For predictive polygons, we used 30x30m polygons to follow the

262

EOSD resolution. For the highway predictions we created polygons around the highway (line

263 feature buffered 15m on each side of highway) resulting in predictions for 7374 polygons.

264 For transect predictions we expanded the buffer around the highway to $1 \mathrm{~km}$, resulting in 
265

266

267

268

269

270

271

272

273

274

275

276

277

278

279

280

281

282

283

284

285

286

287

288

289

213442 polygons. Next, we generated a predictor set for each polygon centroid that was identical to those used for survey points, and then estimated abundance based on our averaged models for each of the focal species groups. We combined individual mammal group abundance estimates into 10 quantiles to consolidate focal species maps into an index of site preference, multiplied those scores for each polygon and standardized them by dividing by 1000, resulting in community site preference scores between 0 (being the lowest preference) and 10 (highest preference).

\section{Results}

We conducted surveys for $737 \mathrm{~km}$ of highway $(\mathrm{H})$ and $118.5 \mathrm{~km}$ of transects $(\mathrm{T})$, that yielded the following number of track counts: deer $=970 \mathrm{H} / 887 \mathrm{~T}$, elk $=575 \mathrm{H} / 152 \mathrm{~T}$, moose $=65 \mathrm{H} / 59 \mathrm{~T}$, coyote $=58 \mathrm{H} / 111 \mathrm{~T}$, bobcat $=6 \mathrm{H} / 11 \mathrm{~T}$, cougar $=1 \mathrm{H} / 11 \mathrm{~T}$, wolf $=0 \mathrm{H} / 10 \mathrm{~T}$, fox $=3 \mathrm{H} / 2 \mathrm{~T}$. No tracks were found for lynx, marten or wolverine (raw data and R model input files can be found in Data S1).

\section{ROAD BARRIER EFFECT}

Highway permeability values for the majority of groups were extremely low (where a value of 1 indicates full permeability across the highway and 0 represents no permeability), indicating that Hwy 3 likely acts as a barrier to mammal movement (Table 2). The permeability values for carnivores were only one third those of ungulates (moose, elk, deer, combined) on the investigated section of Hwy 3 (Table 2), indicating that deer, elk, and moose were much less affected by the highway in terms of movement than carnivores. Track accumulation curves for all mammal groups indicate that in all four cases there were areas of the highway where the focal group rarely or almost never crosses the highway (Figure 2). 


\section{LANDSCAPE VARIABLE PREFERENCE MODELS}

Based on intercept only model comparisons using likelihood ratio tests, Vuong test and AIC ranking, the best supported distributions for each mammal group were: ZINB (DeerHwy, Elk-Hwy, Deer-Trans), NB (Moose-Hwy, Elk-Trans, Carnivora-Trans), ZIP (Carnivora-Hwy) , P (Moose-Trans), indicating that ZINB and NB were the most commonly supported distributions (Table 3). In 6 out of 8 cases, the modeling approach which included predictors from all three scales and the digitized polygons was selected as the top model based on AICc (Table 4). In only two cases for the transect data did other approaches result in lower AICc values: Deer (1 km scale) and Moose (500m scale). In direct comparison between predictors derived from remotely sensed data and hand digitized data, the remotely sensed model framework resulted in lower AICc values in all eight cases. When comparing the remotely sensed data approach at the same scale as the digitized (200m) data, digitized predictors resulted in lower AICc values in 7/8 cases. A comparison of the extended modeling results (Table 4) with the initial distribution tests (Table 3) indicates that in 4/8 cases the results from the initial tests were rejected and different distributions formed the basis of models with the lowest AICc values. For Highway and Transect data from each mammal group, model coefficients describing preferred (positive values) and avoided (negative values) habitat variables from the best supported model (above) are depicted in Tables S1 and S2. Summed values of preferred and avoided landscape variables for the entire mammal community are presented in Table 5.

\section{PREDICTIVE MAPS OF PREFERRED CROSSING SITES}

To map preferred crossing sites, we used averaged model results for each mammal group based on the framework with the lowest AICc value out of the 4 remotely sensed model sets (Cells marked with an asterisk in Table 4; maps and shapefiles in Figures S1-S4 
and Data S2 respectively). The combined predictions of preferred (green) and avoided (red) crossing sites for all investigated species within the mammal community are illustrated in

317 Fig. 3. Based on predictions generated from landscape variables (above), certain regions of 318 the study area exhibited high preference scores from both approach (transect) and crossing 319 (highway) models (e.g., Fig. 3 insert A), indicating that these locations likely represent areas 320 of high priority when implementing mitigation measures for all species considered in our study. Conversely, certain regions of the study area exhibited high preference scores for one of the model sets (crossing vs. approach), but not the other (e.g., Fig. 2 insert B), indicating that these may represent less-ideal locations to implement mitigation measures such as crossing structures. Areas of unambiguous preference for particular crossing sites (i.e., those where crossing and approach preference scores overlap) differ for each mammal group considered in our study (Figures S1-S4), indicating that mitigation strategies aimed at mammal communities may differ substantially from those aimed at a target species.

\section{Discussion}

We determined that Hwy 3 posed a severe movement barrier to the local mammal community. Although each investigated species differed in the landscape variables associated with preferred and avoided crossing sites, we used a multi-scale approach to identify locations along the highway where mitigation measures may benefit all species in the large mammal community. Below we address our earlier questions and discuss the implications of our finding that multi-scale habitat assessments may be necessary to accurately predict the most effective locations for highway crossing structures (e.g., culverts and overpasses) or other mitigation measures. 
340 acts as barrier to animal movement. Although permeability estimates for elk were comparatively high (likely due to herding behavior, whereas tracks for all other species

342 tended to be solitary or in small groups), averaged estimates for all ungulates and the entire

343 mammal community suggest that movement by large-bodied mammals is highly restricted

344 across the highway. Likewise, track accumulation curves (Figure 2) indicate that for each

345 species group considered, certain areas of the highway may rarely or never be crossed, posing

346 large limitations to population connectivity across Hwy 3. This finding is consistent with

347 previous estimates of wildlife permeability across a similar highway through the Rocky

348 Mountain Range of Alberta, Canada (Alexander, Waters, \& Paquet, 2005). Such low

349 permeability across the highway suggests a severe threat of habitat fragmentation to the

350 mammal community, which could result in decreased gene flow across the road barrier, and

351 ultimately to lower population viability in the region (Mader, 1984; Epps et al., 2005). These results indicate a need to accurately identify locations for potential mitigation measures along roads such as Hwy 3 to facilitate the movement of individuals across the highway and reduce this barrier effect (Harrison \& Bruna, 1999; Haddad et al., 2003; Crooks \& Sanjayan, 2006).

By incorporating both highway and transect predictions simultaneously, we aimed to identify locations for potential mitigation measures that represent both preferred crossing sites as well as preferred approach habitat up to $1 \mathrm{~km}$ from the highway. We determined that the landscape variables associated with preferred/avoided crossing sites differed for many of the mammal groups considered (Tables S1, S2). In all cases, noise generated from vehicles travelling on the highway could contribute to road avoidance by large mammals (Forman \&

361 Alexander, 1998; Jaeger et al., 2005; Barber, Crooks, \& Fristrup, 2010). However, numerous

362 studies on movement across roads by large and small mammals have found no consistent 363 response to noise levels, and suggest that habitat characteristics surrounding crossing sites 364 play a larger role in animal movement than individual tolerance to noise levels (McGregor, 
365 Bender, \& Fahrig, 2008; Iglesias, Mata, \& Malo, 2012). For instance, carnivores tended to avoid residential areas along the highway as well as open areas with low shrub cover (Tables S1, S2), consistent with previous studies (e.g. Mech, 1995). While elk and deer did not avoid these landscape features, these two species exhibited dissimilar patterns of habitat and crossing-site preference, consistent with their different habitat requirements (Johnson et al., 2000). These differing results per group indicate that a clear set of conservation goals for each species as well as the community as a whole must be established before mitigation measures are implemented to facilitate highway crossing (e.g. Beier, Majka, \& Spencer, 2008).

We used multi-model inference and model averaging to identify locations of preferred crossing sites for all mammal species considered, which would likely serve as the most effective locations for mitigation measures aimed at increasing mammal permeability across the highway. Cumulative scores of preferred/avoided landscape variables along both the highway and transect data sets indicate that preferred crossing sites tended to be within close proximity of water and longer stretches of unpaved road (Table 5). Crossing-specific scores indicate a preference for longer stretches of paved roads, and approach-specific scores suggest preference for areas of high crown cover with abundant broadleaf trees, respectively. Although this approach may reduce the efficiency of predicting highway crossing sites for certain focal species, community-level approaches are increasingly advocated as a more efficient means of implementing wildlife linkages across barriers such as major roads (Beier, Majka, \& Spencer, 2008). To accomplish this goal, we applied an exhaustive model approach incorporating four separate distributions of abundance for each mammal group along Hwy 3. In only 4 of the 8 cases considered was pre-selection of the y-distribution successful, indicating that an exhaustive modeling approach incorporating multiple distributions may be necessary when the goal is to identify and predict preferred crossing sites based on limited 
data and uncertainties regarding which abundance distributions are most applicable to free-

391 living animal populations. By adopting the approach described here, researchers may be able

to extract more information from highway crossing data than could otherwise be gained from applying predefined and potentially inaccurate abundance distributions. Further, the bestsupported distribution differed for each species; while ZINB and NB were the most commonly supported distributions, NB, ZIP and P each received the best support for at least one data set (highway versus transect). These results once again highlight the need for future studies to consider the unique habitat requirements of each species within mammal communities when developing mitigation strategies, but that those strategies which provide the greatest benefit to the largest number of species should be given priority for implementation.

To establish conservation-based goals for large mammals along roads such as Hwy 3, further consideration must be given to whether the spatial scales at which habitat characteristics are measured match the spatial scales at which the animals select

404 preferred/avoided crossing sites. We determined that in 6/8 cases, a combined approach to 405 modeling preferred crossing sites (incorporating remotely sensed and hand-digitized 406 predictors) resulted in the best supported model. Further, utilizing multi-scale remote sensing-derived predictors always resulted in better model support than utilizing only handdigitized predictors for each species and data set considered. Thus, our results indicate that

409 while a combined approach may represent the most informative method for predicting

410 landscape variables of preferred mammal crossing sites, freely-available macro-habitat data

411 such as those generated through remote sensing may be more useful than labor-intensive

412 micro-habitat assessments when time and budgetary constraints on data collection are

413 imposed. Previous studies investigating habitat occupancy in birds have found similar results 414 (e.g. McClure, Rolek, \& Hill, 2012; Meiman et al., 2012), highlighting the increasing 
415 usefulness of remote sensing in evaluating localized questions in conservation and 416 community ecology.

417 The goal of our study was to identify locations along Hwy 3 where mitigation

418 measures might increase connectivity across the highway for all species in the mammal

419 community. Although we do not currently have data on which mitigation measures may be

420 the most effective on increasing permeability in this system, previous studies investigating

421 the costs/benefits of different mitigation strategies at the community level (e.g. Clevenger \&

422 Waltho, 2000, 2005) indicate that a diversity of crossing structures of different sizes may best

423 serve large mammal communities. Because our permeability estimates were based on snow

424 tracks and not on data for the entire year, there is the potential for our results to only be

425 applicable for winter months. Further, because our permeability estimates are based on

426 transects with a mean distance of $175 \mathrm{~m}$ from the highway, we likely overestimate

427 permeability in certain cases by not considering the density of animals in areas further away

428 from the highway. For instance, Dickson \& Beier (2002) determined that cougars typically

429 avoid high speed roads at a distance of $500 \mathrm{~m}-1 \mathrm{~km}$ and more generally, mammal

430 populations might be influenced by human infrastructure up to about 5km (Benítez-López,

431 Alkemade, \& Verweij, 2010). Although conducting further transects at a greater distance

from the road may improve estimates of habitat preference for each species along Hwy 3, we

433

believe our methods represent a realistic investigation of the types of habitat used by animals

434 approaching and ultimately crossing the road, which may help inform strategies for

435 implementing crossing structures. A potential limitation to our approach of determining the most appropriate locations for multi-species crossing structures is that preferred landscape traits differed among groups, indicating that some species would benefit less from crossing sites that serve the majority (for species specific preferences see Figures S1-S4). While the specifics of which species should be given priority in such an instance will depend on the 
conservation goals of managers, our method presents a potentially viable way of increasing

441 highway permeability for multiple species, and ultimately improving connectivity and

442

443

444

445

446

447

448

449

450

451

452

453

454

455

456

457

458

459

460

461

462

463

population viability for mammal communities along major roadways.

Although our study was limited to one section of highway, its importance as a wildlife

corridor suggests that our approach may be widely applicable to other areas where roads

bisect important wildlife habitat. In situations where managers are capable of implementing

mitigation measures aimed at increasing cross-road permeability for multiple mammal

species, future studies should seek to evaluate the efficiency of this method over traditional

single-species approaches. Specifically, to verify the effectiveness of our approach compared

to a single- species mitigation strategy, managers would ideally implement our method in areas where traditional mitigation approaches have been in place for a number of years. By

directly comparing permeability values before and after the implementation of a multiplespecies mitigation approach, we may gain further insight into benefits of community-level conservation planning.

Finally we would like to acknowledge that our modeling approach only constitutes one possible way of drawing inference about highway approach and crossing behavior of the investigated mammal community. Here, we provide a flexible but somewhat restrictive framework for predicting animal abundance. Though there is always uncertainty surrounding model choice when using a multi-scale approach, extra caution should be used when basing model choice on 'stepwise' procedures and using p-values to exclude certain models from a set. The use of AIC to rank models is currently widely applied in the literature and is assumed to be valid, but this approach only gives a relative measure of fit for comparing models. AIC does not provide a measure for predictive ability of a model, which should ideally be tested against additional data. Finally, alternatives to model averaging such as a reversible jump 
464 MCMC approach (Green, 1995) could be employed to compare results and further improve 465 robustness of analysis.

466

\section{Conclusion} threat to wildlife habitat, but few studies investigate how or where to implement mitigation measures at the community level. We identified areas along the highway with habitat features of preferred crossing sites for eight species of large mammals, representing locations where mitigation measures may have positive effects for all species investigated. We determined that a combined approach incorporating both remotely sensed and hand-digitized landscape variables best predicted crossing site preference for most species, but that remote sensing data was always better than hand-digitized values when utilized separately. Our results indicate that a multi-scale approach may be necessary when identifying areas to implement mitigation strategies across roads, as differing habitat requirements for members of the mammal community may limit the usefulness of single-species, single-scale approaches.

479

480

\section{Acknowledgments} for helpful advice on data collection and analysis, and W. Desch for initial methodological 


\section{Literature cited}

490 Alexander, S., Waters, N., \& Paquet, P. 2005. Traffic volume and highway permeability for a 491 mammalian community in the Canadian Rocky Mountains. Canadian Geographer-Geographe 492 Canadien 49(4):321-331.

493 Barber, J. R., Crooks, K. R., \& Fristrup, K. M. 2010. The costs of chronic noise exposure for 494 terrestrial organisms. Trends in Ecology \& Evolution 25(3):180-189.

495 Barton, K. 2012. MuMIn: Multi-model inference 1.8.0, http://cran.r496 project.org/package=MuMIn.

497 Beaudry, F., deMaynadier, P. G., \& Hunter, M. L. 2008. Identifying road mortality threat at 498 multiple spatial scales for semi-aquatic turtles. Biological Conservation 141(10):2550-2563.

499 Beier, P., Majka, D. R., \& Spencer, W. D. 2008. Forks in the road: Choices in procedures for 500 designing wildland linkages. Conservation Biology 22(4):836-851.

501 Beier, P., \& Noss, R. F. 1998. Do habitat corridors provide connectivity? Conservation 502 Biology 12(6):1241-1252.

503 Benítez-López, A., Alkemade, R., \& Verweij, P. A. 2010. The impacts of roads and other 504 infrastructure on mammal and bird populations: a meta-analysis. Biological Conservation 505 143(6):1307-1316.

506 Bennett, A. F. 1991. Roads, roadsides and wildlife conservation: a review. In D. A. Saunders 507 \& R. J. Hobbs (Eds.), Nature Conservation 2: the Role of Corridors. (pp. 99-118). New South 508 Wales: Surrey Beatty and Sons. 
509 Beyer, H. L. 2012. Geospatial Modelling Environment (Version 0.7.2.1). (software). URL:

510 http://www.spatialecology.com/gme.

511 Boyce, M. S. 1992. Population viability analysis. Annual Review of Ecology and

512 Systematics 23:481-506.

513 Boyce, M. S., Mao, J. S., Merrill, E. H., Fortin, D., Turner, M. G., Fryxell, J., \& Turchin, P.

514 2003. Scale and heterogeneity in habitat selection by elk in Yellowstone National Park.

515 Ecoscience 10(4):421-431.

516 British Columbia Ministry of Transportation and Infrastructure. 2010. Traffic Data Program.

517 Burnham, K. P., \& Anderson, D. R. 2002. Model selection and multimodel inference: $a$

518 practical information-theoretic approach. New York, NY: Springer Verlag.

519 Clevenger, A. P., \& Waltho, N. 2000. Factors Influencing the Effectiveness of Wildlife 520 Underpasses in Banff National Park, Alberta, Canada. Conservation Biology 14(1):47-56.

521 Clevenger, A. P., \& Waltho, N. 2005. Performance indices to identify attributes of highway 522 crossing structures facilitating movement of large mammals. Biological Conservation 523 121(3):453-464.

524 Crooks, K. R. 2002. Relative sensitivities of mammalian carnivores to habitat fragmentation.

525 Conservation Biology 16(2):488-502.

526 Crooks, K. R., \& Sanjayan, M. 2006. Connectivity conservation: maintaining connections for

527 nature. In K. R. Crooks \& M. Sanjayan (Eds.), Connectivity conservation (pp. 1-20).

528 Cambridge: Cambridge University Press. 
529 Dickson, B., \& Beier, P. 2002. Home-range and habitat selection by adult cougars in

530 southern California. The Journal of wildlife management 66(4):1235-1245.

531 Dickson, B. G., Jenness, J. S., \& Beier, P. 2005. Influence of vegetation, topography, and

532 roads on cougar movement in southern California. Journal of Wildlife Management

533 69(1):264-276.

534 Elbroch, M. 2003. Mammal tracks \& sign: a guide to North American species. (M. Elbroch, 535 Ed.). Stackpole Books, Pennsylvania, USA.

536 Epps, C. W., Palsboll, P. J., Wehausen, J. D., Roderick, G. K., Ramey, R. R., \& McCullough, 537 D. R. 2005. Highways block gene flow and cause a rapid decline in genetic diversity of desert 538 bighorn sheep. Ecology Letters 8(10):1029-1038.

539 ESRI. 2009. ArcGIS 9.3. Economic and Social Reserach Institute Inc., Redlands, CA.

540 http://www.esri.com/.

541 ESRI. 2010. ArcGIS 10. Economic and Social Reserach Institute Inc., Redlands, CA.

542 http://www.esri.com/.

543 Fahrig, L., \& Rytwinski, T. 2009. Effects of roads on animal abundance: an empirical review 544 and synthesis. Ecology and Society 14:21.

545 Fearer, T. M., Prisley, S. P., Stauffer, D. F., \& Keyser, P. D. 2007. A method for integrating

546 the Breeding Bird Survey and Forest Inventory and Analysis databases to evaluate forest

547 bird-habitat relationships at multiple spatial scales. Forest Ecology and Management

$548 \quad 243(1): 128-143$. 
549 Forman, R. T. T., \& Alexander, L. E. 1998. Roads and their major ecological effects. Annual 550 Review of Ecology and Systematics 29:207-231.

551 Gonzalez, A., Lawton, J. H., Gilbert, F. S., Blackburn, T. M., \& Evans-Freke, I. 1998.

552 Metapopulation dynamics, abundance, and distribution in a microecosystem. Science 553 281(5385):2045-2047.

554 Green, P. J. 1995. Reversible jump Markov chain Monte Carlo computation and Bayesian 555 model determination. Biometrika 82(4):711-732.

556 Greene, W. H. 1994. Accounting for excess zeros and sample selection in Poisson and 557 negative binomial regression models (p. 34). New York University Leonard N. Stern School 558 of Business.

559 Guisan, A., \& Thuiller, W. 2005. Predicting species distribution: offering more than simple 560 habitat models. Ecology Letters 8(9):993-1009.

561 Haddad, N. M., Bowne, D. R., Cunningham, A., Danielson, B. J., Levey, D. J., Sargent, S., \& 562 Spira, T. 2003. Corridor use by diverse taxa. Ecology 84(3):609-615.

563 Harrison, S., \& Bruna, E. 1999. Habitat fragmentation and large-scale conservation: what do 564 we know for sure? Ecography 22(3):225-232.

565 Hilbe, J. 2008. Negative Binomial Regression (p. 251). Cambridge University Press New 566 York.

567 Holderegger, R., \& Di Giulio, M. 2010. The genetic effects of roads: A review of empirical 568 evidence. Basic and Applied Ecology 11(6):522-531. 
569 Iglesias, C., Mata, C., \& Malo, J. E. 2012. The Influence of Traffic Noise on Vertebrate Road 570 Crossing Through Underpasses. Ambio 41(2):193-201.

571 Jackman, S. 2012. pscl: Classes and Methods for R Developed in the Political Science

572 Computational Laboratory, Stanford University. http://pscl.stanford.edu/. Stanford, 573 California.

574 Jaeger, J. A. G., Bowman, J., Brennan, J., Fahrig, L., Bert, D., Bouchard, J., Charbonneau, 575 N., Frank, K., Gruber, B., \& von Toschanowitz, K. T. 2005. Predicting when animal 576 populations are at risk from roads: an interactive model of road avoidance behavior. 577 Ecological Modelling 185(2-4):329-348.

578 Johnson, B. K., Kern, J. W., Wisdom, M. J., Findholt, S. L., \& Kie, J. G. 2000. Resource 579 selection and spatial separation of mule deer and elk during spring. Journal of Wildlife 580 Management 64(3):685-697.

581 Jones, M. E. 2000. Road upgrade, road mortality and remedial measures: impacts on a 582 population of eastern quolls and Tasmanian devils. Wildlife Research 27(3):289-296.

583 Lambert, D. 1992. Zero-Inflated Poisson Regression, with an Application to Defects in 584 Manufacturing. Technometrics 34(1):1-14.

585 Lingle, S., \& Wilson, W. F. 2001. Detection and Avoidance of Predators in White-Tailed 586 Deer (Odocoileus virginianus) and Mule Deer (O. hemionus). Ethology 107(2):125-147.

587 Mader, H. J. 1984. Animal habitat isolation by roads and agricultural fields. Biological 588 Conservation 29(1):81-96. 

predictive models? Journal of Applied Ecology 41(4):701-710.

591

592

Mayor, S. J., Schaefer, J. A., Schneider, D. C., \& Mahoney, S. P. 2007. Spectrum of selection: new approaches to detecting the scale-dependent response to habitat. Ecology 88(7):1634-1640.

McClure, C. J. W., Rolek, B. W., \& Hill, G. E. 2012. Predicting Occupancy of Wintering Migratory Birds : Is Microhabitat Information Necessary? The Condor 114(3):482-490.

McGregor, R. L., Bender, D. J., \& Fahrig, L. 2008. Do small mammals avoid roads because of the traffic? Journal of Applied Ecology 45(1):117-123.

Mech, L. D. 1995. The challenge and opportunity of recovering wolf populations.

Conservation Biology 9(2):270-278.

Meidinger, D., \& Pojar, J. 1991. Ecosystems of British Columbia. Victoria, BC: British Columbia Ministry of Forests.

Meiman, S., Civco, D., Holsinger, K., \& Elphick, C. S. 2012. Comparing Habitat Models Using Ground-Based and Remote Sensing Data: Saltmarsh Sparrow Presence Versus Nesting. Wetlands 32(4):725-736.

Noss, R. F., \& Cooperrider, A. Y. 1994. Saving nature’s legacy: protecting and restoring biodiversity. (R. F. Noss \& A. Y. Cooperrider, Eds.). Island Press, Washington D.C., USA.

Noss, R. F., Quigley, H. B., Hornocker, M. G., Merrill, T., \& Paquet, P. C. 1996.

Conservation biology and carnivore conservation in the Rocky Mountains. Conservation Biology 10(4):949-963. 
610 R Development Core Team. 2012. R: A language and environment for statistical computing

611 2.15.2, http://www.r-project.org. Vienna, Austria: R Foundation for Statistical Computing.

612 Rawlings, J. O., Pantula, S. G., \& Dickey, D. A. 1998. Applied Regression Analysis: A

613 Research Tool (p. 657). Springer Verlag.

614 Schuster, R., \& Arcese, P. 2013. Using bird species community occurrence to prioritize 615 forests for old growth restoration. Ecography 36(4):499-507.

616 Seiler, A. 2005. Predicting locations of moose-vehicle collisions in Sweden. Journal of 617 Applied Ecology 42(2):371-382.

618 Selva, N., Kreft, S., Kati, V., Schluck, M., Jonsson, B.-G., Mihok, B., Okarma, H., \& Ibisch, 619 P. L. 2011. Roadless and Low-Traffic Areas as Conservation Targets in Europe.

620 Environmental Management 48(5):865-877.

621 Sheldon, L. 1997. Animal Tracks of the Rockies. (L. Sheldon, Ed.). Lone Pine Publishing, 622 Edmonton, Canada.

623 Singleton, P., \& Lehmkuhl, J. 1999. Assessing wildlfie habitat connectivity in the Interstate 62490 Snoqualmie Pass Corridor, Washington. In G. L. Evink, P. Garrett, \& D. Zeigler (Eds.), 625 Proceedings of the third international conference on wildlife ecology and transportation (pp. 626 75-84). Florida Department of Transportation, Tallahassee, Florida, USA.

627 Thompson, I. D., Davidson, I. J., Odonnell, S., \& Brazeau, F. 1989. Use of track transects to 628 measure the relative occurrence of some boreal mammals in uncut forest and regeneration 629 stands. Canadian Journal of Zoology-Revue Canadienne de Zoologie 67(7):1816-1823. 
630 Trombulak, S. C., \& Frissell, C. A. 2000. Review of ecological effects of roads on terrestrial 631 and aquatic communities. Conservation Biology 14(1):18-30.

632 Underhill, J., \& Angold, P. 2000. Effects of roads on wildlife in an intensively modified 633 landscape. Environmental Reviews 8(1):21-39.

634 Van Dyke, F. G., Brocke, R. H., \& Shaw, H. G. 1986. Use of road track counts as indices of 635 mountain lion Felis Concolor presence. Journal of Wildlife Management 50(1):102-109.

636 Venables, W. N., \& Ripley, B. D. 2002. Modern Applied Statistics with S (Fourth.). New 637 York: Springer.

638 Vuong, Q. H. 1989. Likelihood Ratio Tests for Model Selection and Non-Nested Hypotheses. 639 Econometrica 57(2):307-333.

640 White, G. C., \& Burnham, K. P. 1999. Program MARK: survival estimation from populations 641 of marked animals. Bird Study 46(1 supp 1):120-139.

642 Wulder, M. A., White, J. C., Cranny, M., Hall, R. J., Luther, J. E., Beaudoin, A., 643 Goodenough, D. G., \& Dechka, J. A. 2008. Monitoring Canada’s forests. Part 1: Completion 644 of the EOSD land cover project. Canadian Journal of Remote Sensing 34(6):549-562.

645 Yellowstone to Yukon Conservation Initiative. 2013. Y2Y Priority Areas. http://y2y.net/our646 work/priority-areas. Accessed: 2013-March-26.

647 Zeileis, A., \& Croissant, Y. 2010. Extended Model Formulas in R: Multiple Parts and 648 Multiple Responses. Journal of Statistical Software 34(1):1-13.

649 Zeileis, A., Kleiber, C., \& Jackman, S. 2008. Regression models for count data in R. Journal 650 of Statistical Software 27(8):1-25. 